\title{
Pharmacological Treatment of Secondary Lymphedema
}

\section{Stav Brown, Joseph H. Dayan, Michelle Coriddi, Adana Campbell, Kevin Kuonqui, Jinyeon Shin, Hyeung Ju Park, Babak J. Mehrara and Raghu P. Kataru*}

Plastic and Reconstructive Surgery Service, Department of Surgery, Memorial Sloan Kettering Cancer Center, New York, NY, United States

Lymphedema is a chronic disease that results in swelling and decreased function due to abnormal lymphatic fluid clearance and chronic inflammation. In Western countries, lymphedema most commonly develops following an iatrogenic injury to the lymphatic system during cancer treatment. It is estimated that as many as 10 million patients suffer from lymphedema in the United States alone. Current treatments for lymphedema are palliative in nature, relying on compression garments and physical therapy to decrease interstitial fluid accumulation in the affected extremity. However, recent discoveries have increased the hopes of therapeutic interventions that may promote lymphatic regeneration

OPEN ACCESS

Edited by:

Ines Martinez-Corral, INSERM U1172 Centre de Recherche Jean Pierre Aubert, France

Reviewed by:

Barbara Garmy-Susini, Institut National de la Santé et de la Recherche Médicale (INSERM), France

Oliver Lyons,

University of Otago, New Zealand

*Correspondence:

Raghu P. Kataru

katarur@mskcc.org

Specialty section:

This article was submitted to Experimental Pharmacology and Drug

Discovery,

a section of the journal

Frontiers in Pharmacology

Received: 03 December 2021 Accepted: 07 January 2022 Published: 25 January 2022

Citation:

Brown S, Dayan JH, Coriddi M, Campbell A, Kuonqui K, Shin J, Park HJ, Mehrara BJ and Kataru RP (2022) Pharmacological Treatment of Secondary Lymphedema. Front. Pharmacol. 13:828513. doi: 10.3389/fphar.2022.828513 and function. The purpose of this review is to summarize current experimental pharmacological strategies in the treatment of lymphedema.

Keywords: Iymphedema, tacrolimus, tetracyclines, doxycycline, TH2 cells, CD4+, vascular endothelial growth factor C, VEGF-C

\section{INTRODUCTION}

Lymphedema is a disease that is characterized by progressive fibroadipose tissue deposition resulting from impaired lymphatic drainage. (Rockson, 2001; Kataru et al., 2019; Li et al., 2020a) The pathological changes decrease quality of life (QoL) due to chronic swelling, pain, and loss of function. (Beaulac et al., 2002; Heiney et al., 2007; Warren et al., 2007) Some patients with lymphedema also develop recurrent, sometimes severe, skin infections necessitating hospitalization for intravenous antibiotics and prophylactic antibiotics. (Yuan et al., 2019) Though rare, lymphangitis and sepsis can develop and may result in multiorgan failure and death. These physical and functional manifestations result in higher levels of anxiety and depression and a higher likelihood of chronic pain and fatigue among lymphedema patients. (Stolldorf et al., 2016) The treatment of lymphedema is also very costly and is often not covered by insurance. (Shih et al., 2009; De Vrieze et al., 2020)

Decreased lymphatic drainage capacity leading to lymphedema development can occur due to genetic abnormalities of the lymphatic system or, more commonly, secondary to external insults to the lymphatic system such as infections or surgical injury. (Greene and Goss, 2018) In Western countries, the most common cause of lymphedema is an iatrogenic injury to the lymphatic system during surgical management of solid tumors. (Rockson and Rivera, 2008) Lymphedema develops in approximately 1 in 6 patients treated for melanoma, gynecological or urological tumors, and sarcomas. (Cormier et al., 2010) By far, the most common cause of lymphedema is breast cancer treatment due to the high prevalence of this cancer type. (DiSipio et al., 2013) Although the incidence of breast cancer-related lymphedema (BCRL) is variable depending on the type of study, it is generally thought that approximately $15-40 \%$ of all patients who undergo axillary lymph node dissection for breast cancer treatment go on to develop lymphedema. (Cowher et al., 2014; Rockson, 
TABLE 1 | Summary of Risk of Bias among Randomized (ROB2 tool) and Non-randomized Trials (ROBINS-I tool). A. Risk of Bias for Non-randomized Trials.

\begin{tabular}{|c|c|c|c|c|c|c|c|c|c|c|c|}
\hline Treatment & Study & & D1 & \multicolumn{2}{|c|}{ D2 } & D3 & D4 & D5 & D6 & D7 & Overall \\
\hline Lymphangiogenic interventions (BioBridge ${ }^{\mathrm{TM}}$ ) & \multicolumn{2}{|l|}{ Nguyen et al. (2021b) } & Moderate & \multicolumn{2}{|c|}{ Moderate } & Low & Low & Low & Low & Low & Low \\
\hline Lymphangiogenic interventions (Lymfactin ${ }^{\oplus}$ ) & \multicolumn{2}{|l|}{ Hartiala et al. (2020a) } & Moderate & \multicolumn{2}{|c|}{ Moderate } & Moderate & Low & Low & Moderate & Low & Moderate \\
\hline TH2 inhibition with neutralizing antibodies & \multicolumn{2}{|l|}{ Mehrara et al. (2021) } & Moderate & \multicolumn{2}{|l|}{ Low } & Low & Low & Low & Low & Low & Low \\
\hline Treatment & Study & D1 & D2 & & & D3 & D4 & & D5 & & Overall \\
\hline Lymphangiogenic interventions (Lymfactin ${ }^{\circledR}$ ) & Hartiala et al. (2020b) & Low & No inform & ation & High & & Low & & No information & No & information \\
\hline $\mathrm{LTB}_{4}$ Inhibitors & Rockson et al. (2018) & Low & Low & & Low & & Some col & cerns & Low & Lov & \\
\hline Tetracyclines & Debrah et al. (2006) & Low & Low & & Some & concerns & Some col & cerns & Some concerns & Sol & ne concerns \\
\hline Tetracyclines & Mand et al. (2012) & Low & Low & & Low & & Some col & cerns & Low & Lov & \\
\hline
\end{tabular}

D1: Bias due to confounding.

D2: Bias due to selection of participants.

D3: Bias in classification of interventions.

D4: Bias due to deviations from intended interventions.

D5: Bias due to missing data.

D6: Bias in measurement of outcomes.

D7: Bias in selection of the reported result.

B. Risk of Bias for Randomized Trials.

D1: Bias arising from the randomization process.

D2: Bias due to deviations from intended intervention.

D3: Bias due to missing outcome data.

D4: Bias in measurement of the outcome.

D5: Bias in selection of the reported result.

2018; Salinas-Huertas et al., 2021) Patient-related or treatment factors including radiation, taxane chemotherapy agents, and obesity increase the risk of developing secondary lymphedema after cancer surgery. (Shih et al., 2009; DiSipio et al., 2013; Lee et al., 2014; Mehrara and Greene, 2014; Allam et al., 2020) Other studies have suggested that the risk of lymphedema increases with aging and with increasing numbers of lymph nodes removed during surgery. (Guliyeva et al., 2021; Jung et al., 2021) Genetic and sex-linked factors also increase the risk of developing secondary lymphedema. (Finegold et al., 2008; Finegold et al., 2012; Miaskowski et al., 2013) While both primary and secondary lymphedema are more prevalent in women, the role of sex hormones and gender in lymphatic development and function in both physiological and pathological states has yet to be fully deciphered. However, recent studies have increased our understanding of the effects of sex hormones in lymphedema. (Trincot and Caron, 2019; Morfoisse et al., 2021) In addition, sex differences have diverse effects on innate and adaptive immune responses and may also module the risk of lymphedema development. (Klein and Flanagan, 2016)

Despite the high economic and patient costs of lymphedema, current treatment options for most patients with this disease are palliative in nature, focusing on compression garments and manual lymphatic drainage to prevent fluid accumulation rather than addressing the root cause of the disease-lymphatic injury. (Uzkeser et al., 2015; Dayan et al., 2018; Barufi et al., 2021) Lifestyle interventions such as exercise and weight loss are also commonly advocated and can improve the symptoms of the disease but are difficult to maintain; this is an important limitation since lymphedema is a lifelong disease. (Schmitz et al., 2019; Keith et al., 2020) More recently, surgical treatment options have been developed for patients with lymphedema; However, these procedures are not always successful, may not be helpful for patients with severe disease, and can result in complications and morbidity. (Carl et al., 2017; Kayıran et al., 2017; Dayan et al., 2018) Therefore, developing effective, non-invasive treatments for lymphedema that address the pathologic effects of the disease-inflammation, fibrosis, and adipose deposition-is an important goal.

While several reviews have described the potential use of pharmacotherapy agents investigated in clinical studies, the current review aims to summarize both preclinical studies and clinical trials of a wide range of pharmacological strategies to provide a broad view of their potential utility for use in lymphedema. (Badger et al., 2004a; Forte et al., 2019a; Forte et al., 2019b; Forte et al., 2019c; Forte et al., 2019d; Walker et al., 2021) Risk of bias for clinical studies was assessed through the revised Cochrane Risk of Bias tool for randomized controlled trials (RoB2) and Risk of Bias in Non-randomized Studies - of Interventions" (ROBINS-I) tools (Table 1). (Sterne et al., 2016; Sterne et al., 2019)

\section{PHARMACOLOGICAL INTERVENTIONS FOR SECONDARY LYMPHEDEMA}

Historically, the pathophysiology of lymphedema was thought to be related to impaired collateral lymphatic vessels formation following surgical injury. (Li et al., 2020b) As a result, many previous studies focused on strategies to improve regeneration of lymphatic vessels using the delivery of lymphangiogenic cytokines. ( $\mathrm{Li}$ et al., 2020b) However, there is increasing evidence that the pathophysiology of lymphedema is more complex and that increasing lymphangiogenesis alone may not be sufficient to treat the disease. More recent studies have targeted chronic inflammatory reactions in lymphedematous tissues to 


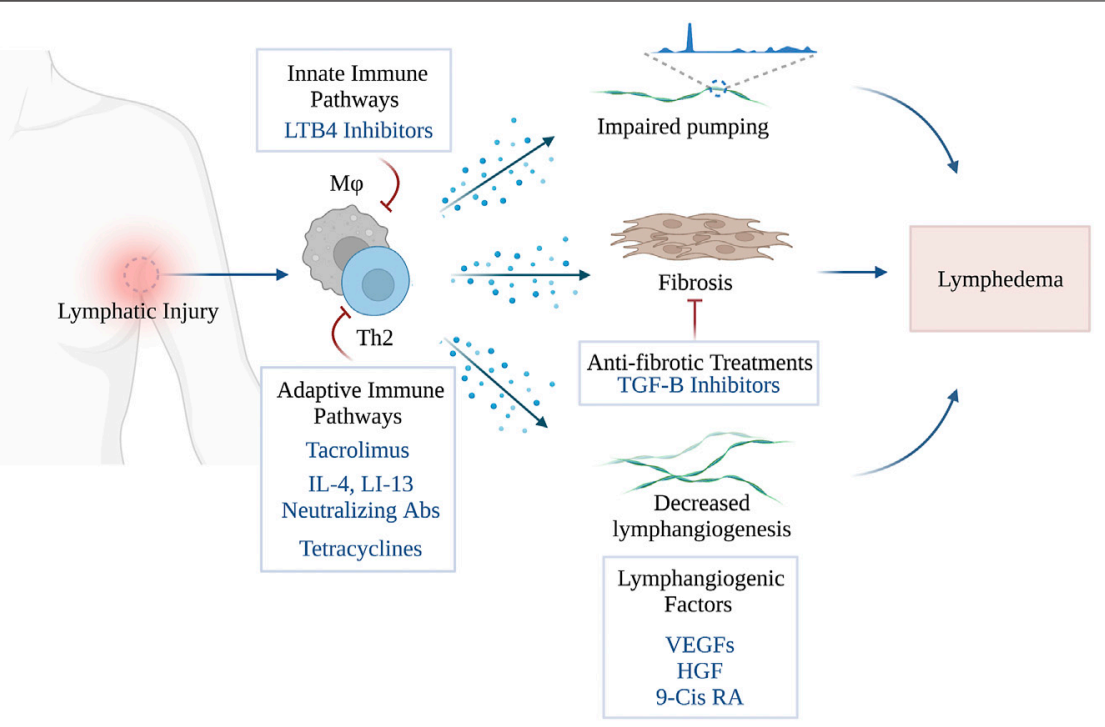

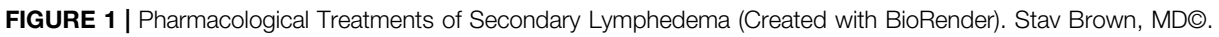

decrease fibrosis, decrease lymphatic leakiness, improve collateralization, and increase collecting lymphatic pumping.

The main therapeutic strategies for the treatment lymphedema consisting of lymphangiogenic interventions, anti-inflammatory treatments and anti-fibrotic agents are summarized in this review (Figure 1). Other treatments for lymphedema have also been reported (e.g., benzopyrones, platelet rich plasma, stem cell therapies), however, these are beyond the scope of the current manuscript and reviewed elsewhere. (Badger et al., 2004b; Forte et al., 2019e; Walker et al., 2021)

\section{LYMPHANGIOGENIC INTERVENTIONS FOR LYMPHEDEMA}

\section{Vascular Endothelial Growth Factors}

VEGFs are a family of growth factors-VEGF-A, VEGF-B, VEGF$\mathrm{C}$, and VEGF-D-that regulate differentiation, proliferation, survival, and migration of blood and lymphatic endothelial cells (BECs and LECs, respectively). (Oliver, 2004; Olsson et al., 2006) VEGF-C and VEGF-D are high-affinity ligands for the tyrosine kinase receptor VEGFR3, highly expressed in both angiogenic BECs and LECs, and serves as a critical regulator of angiogenesis and lymphangiogenesis. (Oh et al., 1997; Mäkinen et al., 2001a; Mäkinen et al., 2001b; Veikkola et al., 2001; Pytowski et al., 2005; Zarkada et al., 2015; Dayan et al., 2018) Mice with homozygous deletion of Vegf-c die in utero and have severe lymphatic malformations. (Haiko et al., 2008) Indeed, VEGFC or VEGF-D activation of VEGFR3 is a key regulator of lymphatic vessel sprouting, LEC proliferation, migration, differentiation, and expression of endothelial nitric oxide synthase (eNOS). (Lahdenranta et al., 2009; Secker and Harvey, 2021) Heterozygous de novo and inherited VEGFR3 mutations have been identified in a congenital or infantileonset form of lymphedema known as Milroy disease.
(Ghalamkarpour et al., 2009; Connell et al., 2013; Online Mendelian Inheritance in Man, 2021) Transgenic mice that express a soluble (i.e., inactivating) form of VEGFR3 have impaired fetal lymphangiogenesis, regression of lymphatic vessels, and a lymphedema-like phenotype including hindlimb swelling and dermal fibrosis. (Mäkinen et al., 2001a)

The observation that treating transgenic mice with a heterozygous inactivating Vegfr-3 mutation-a mouse model of primary lymphedema-using virus-mediated VEGF-C gene therapy increased lymphangiogenesis and formation of functional lymphatics led to the hypothesis that these treatments may also be effective for the treatment of secondary lymphedema. (Karkkainen et al., 2001) This hypothesis was supported by follow-up studies in which recombinant VEGF-C was used in animal models of secondary lymphedema. For example, Szuba and colleagues showed that a single $100 \mu \mathrm{g}$ dose of recombinant human VEGF-C into the surgical bed of a rabbit ear model of lymphedema resulted in histologic evidence of lymphangiogenesis, decreased dermal hypercellularity, and improvements in Indocyanine Green (ICG)-based quantifications of lymphatic function compared to controls. (Szuba et al., 2002) In follow-up studies, this group also showed that delivery of recombinant human VEGF-C improved outcomes in a mouse tail model of lymphedema by increasing lymphangiogenesis, improving the morphology of cutaneous lymphatic vessels, and the ability of lymphatic channels to transport immune cells. (Cheung et al., 2006; Jin et al., 2009)

Topical formulations of VEGF-C have been developed to avoid direct injections of the growth factor and to elicit sustained release. These studies have used acidic gelatin hydrogels to generate a sustained release of biologically active VEGF-C. (Hwang et al., 2011) Combining VEGF-C hydrogel with extracorporeal shock wave therapy or adipose-derived stem 
cells (ADSCs) was even more effective in reducing edema and increasing lymphangiogenesis. (Kim et al., 2013) Indeed, ADSCs alone have been shown to increase lymphatic regeneration and acquire a lymphatic endothelial phenotype in a mouse tail model of lymphedema. (Conrad et al., 2009) Other studies have shown that ADSCs increase lymphangiogenesis by secreting lymphangiogenic growth factors. (Yan et al., 2011; Ahmadzadeh et al., 2020)

Other groups have incorporated recombinant VEGF-C in nanofibrillar collagen scaffolds (BioBridge ${ }^{\mathrm{TM}}$ ) designed to guide lymphangiogenesis across an area of obstruction. (Hadamitzky et al., 2016) Using a porcine model, control animals that underwent lymphatic ligation were compared with animals treated with BioBridge alone or with BioBridge ${ }^{\mathrm{TM}}$ with autologous lymph node transplantation. Three months following surgery, animals treated with BioBridge ${ }^{\mathrm{TM}}$, with or without lymph node transplantation, had decreased bioimpedance ratio-a measure of fluid accumulation in the skin-suggesting that this treatment increased functional lymphatic regeneration. In follow-up studies using a rat lymphedema model, the authors compared control animals that had undergone lymphadenectomy with those implanted with BioBridge ${ }^{\mathrm{TM}}$ with or without autologous ADSCs. Four months after surgery, animals treated with BioBridge ${ }^{\mathrm{TM}}$ (with or without ADSCs) had decreased swelling and increased lymphatic collateralization towards other lymph node drainage basins. (Nguyen et al., 2021a) The efficacy of the device was also retrospectively reviewed following implantation in patients treated with scar release and vascularized lymph node transplantation (VLNT) or lymphovenous anastomosis (LVA) for treatment of secondary lymphedema of the upper or lower extremity. (Danielle et al., 2019) ICG fluorescence lymphography in a patient treated with VLNT and BioBridge demonstrated qualitatively decreased dermal backflow at the site of device implantation and dynamic uptake of ICG in the newly formed collectors draining into the area where VLNT was performed. The authors noted complete or nearly complete edema reduction in two patients with mild lower extremity lymphedema treated with BioBridge implantation and LVA and one patient with a moderate disease of the upper extremity treated with BioBridge ${ }^{\mathrm{TM}}$ and VLNT. These interesting results were followed up by a retrospective cohort study of 29 patients with stage I-III lymphedema of the upper or lower extremity treated with LVA or VLNT with $(n=18$ patients $)$ or without $(n=11$ patient) BioBridge ${ }^{\mathrm{TM}}$ implantation. (Nguyen et al., 2021b) At 1-year follow-up, the authors reported significantly decreased edema in patients treated with LVA or VLNT and implanted with BioBridge ${ }^{\mathrm{TM}}$ as compared to patients treated with surgery alone (although the patients treated with LVA or VLNT also showed improvements). Lymphatic mapping with ICG quantitatively showed more collectors and decreased dermal backflow in patients implanted with BioBridge. These findings are very exciting and require further study in a randomized control trial.

Recombinant VEGF-C is expensive, and its use in large series of animal experiments is cost-prohibitive. As a result, some authors have utilized gene therapy methods to increase VEGFC expression in lymphedema models. Local delivery of naked plasmid VEGF-C DNA in the rabbit ear or mouse tail models increases VEGFR3 expression, decreases swelling and fibroadipose tissue deposition, and improves lymphatic function as assessed using lymphoscintigraphy. (Yoon et al., 2003) Similar results were noted by Liu et al. using a rat hindlimb model of secondary lymphedema. (Liu et al., 2008)

The low efficiency of naked plasmid technique led other groups to develop viral vectors for VEGF-C delivery. Saaristo et al. developed a VEGFR3 specific VEGF-C isoform (VEGFC156S) since VEGF-C activation of VEGFR2 results in blood vessel proliferation and tissue edema. (Saaristo et al., 2002) Delivery of VEGF-C156S using an adenoviral vector to a mouse model of primary lymphedema improved lymphangiogenesis without blood vascular effects. These observations led to the development of adeno-associated viral vectors (AAV) for VEGF-C delivery since AAV vectors elicit decreased host inflammatory responses and mediate longer-term delivery of the construct compared with adenoviral vectors. (Lai et al., 2002)

Administration of AAV-VEGF-C and VEGF-C vectors to the site of surgical injury increases regeneration and differentiation of lymphatic vessels after lymph node dissection in porcine and mouse models. (Tammela et al., 2007; Lähteenvuo et al., 2011) Similarly, delivery of adenoviral VEGF-C either in the lymph node or in the tissues surrounding it increases regrowth of lymphatic vessels and preserves the architecture of the lymph node compared with controls. (Honkonen et al., 2013) These findings suggest that VEGF-C delivery may be helpful for patients treated with autologous VLNT-a surgical treatment for lymphedema. This hypothesis is further supported by other studies demonstrating that lymphatic regeneration following VLNT is associated with increased VEGF-C expression and that injections of recombinant VEGF-C increase lymphatic regeneration and reconnection in autologous transplanted lymph node fragments. (Sommer et al., 2012; Schindewolffs et al., 2014; Huang et al., 2016)

Positive results with preclinical models of VEGF-C delivery in combination with VLNT led to human phase I and phase II clinical trials; Lymfactin ${ }^{\otimes}$ is an investigational adenoviral type 5based gene therapy vector that expresses human VEGF-C. (Hartiala et al., 2020a) A phase I clinical trial reported the use of Lymfactin ${ }^{\otimes}$ in 15 patients with breast cancer-related lymphedema who underwent lymph node transplantation and lymfactin injections of various doses (NCT02994771). The authors reported no dose-limiting toxicities and, at 1year follow-up, they noted that the drug was well tolerated. Two patients developed infections in the lymphedema limb requiring hospitalization; however, infections occur commonly with lymphedema and could not be definitively attributable to the drug. A follow-up phase 2 double-blind, randomized, placebo-controlled, multicenter clinical trial with 39 patients with 12-months follow-up was reported as accruing patients in an abstract published in Cancer Research Communications (NCT03658967) (Hartiala et al., 2020b); however, a final report has not been published in peer-reviewed journals. The study was inconclusive in a company press report. (Herantis Pharma Plc, 2021) Nevertheless, the drug was generally safe and 
well-tolerated. It is unclear if the company plans to continue drug development.

The advent of mRNA-based gene delivery techniques has garnered significant attention recently due to the success of novel COVID-19 vaccines utilizing this approach. These vaccines use nucleoside-modified mRNA encapsulated in lipid nanoparticles (LNPs) and have been shown to be safe and effective in various preclinical models. (Pardi et al., 2018; Magadum et al., 2019; Sahu et al., 2019; Polack et al., 2020; Baden et al., 2021; Skowronski and De Serres, 2021; Wang, 2021) Nucleoside-modified mRNA have several advantages to adenovirus and adeonoassociated virus vectors, including lack of potential integration into the host genome, no pre-existing anti-vector immunity, the potential for repeated treatments without inflammatory or immune sequela, controlled and transient protein production, and decreased manufacturing costs. (Brown et al., 2020)

Szoke et al. recently reported on the use of nucleoside modified VEGF-C mRNA delivered using lipid nanoparticles to promote organ-specific lymphangiogenesis and treat experimentally induced lymphedema. (Szőke et al., 2021) They showed that injection of the VEGF lipid nanoparticles increased VEGF-C expression locally for as long as 20 days after treatment. This increased VEGF-C production significantly increased lymphangiogenesis that persisted even 60 days after injection. Importantly, the authors showed that intradermal injections did not induce significant blood vessel proliferation locally or in other organ systems, induce immune response activation, or have offtarget effects in the lungs or small intestines. This is important since adenoviruses and AAVs can increase gene expression in other organ systems after systemic absorption. Most importantly, the authors reported that a single VEGF-C mRNA lipid nanoparticle injection significantly increased edema formation and adipose deposition in a mouse hindlimb model of lymphedema.

Although VEGF-C treatments have shown potential for clinical application, several lines of experimental and clinical evidence suggest that a cautious approach is needed. One interesting finding is that the expression of VEGF-C is increased in lymphedematous tissues (and serum) and may contribute to increased interstitial fluid accumulation. (Jensen et al., 2015) Thus, it is unclear why increasing the concentration of a cytokine that is already increased in lymphedematous tissues may be a clinically effective means of treating lymphedema. The reasons for this paradoxical increase in VEGFC remain unknown. However, based on our observations in preclinical models, our group has suggested that the increased concentration of VEGF-C is counterbalanced by increased expression of antilymphangiogenic cytokines (e.g., TGF-B1, interferon gamma, IL4, IL13) that decrease lymphatic endothelial proliferation and increase lymphatic leakiness. (Kataru et al., 2011; Gardenier et al., 2017; Gousopoulos et al., 2017; Park et al., 2018) Anti-lymphangiogenic cytokines can directly decrease responsiveness of lymphatic endothelial cells to VEGF-C thus decreasing the efficacy of exogenous VEGF-C delivery for the treatment of lymphedema. (Savetsky et al., 2015; Shin et al., 2015; Ogata et al., 2016) This hypothesis is supported by the finding that VEGF-C overexpression induces transient lymphatic hyperplasia but does not improve lymphatic function in the mouse tail model of lymphedema. (Goldman et al., 2005) It is also possible that over-expression of VEGF-C increases inflammation and blood vessel leakiness thus contributing to increased swelling. (Gousopoulos et al., 2017) Taken together, these findings suggest that the pathophysiology of lymphedema is more complex than a simple deficiency of VEGF-C (or other lymphangiogenic cytokines) and may explain why surgical interventions that decrease scarring or improve lymphatic function are necessary as adjuncts to exogenous VEGF-C delivery for optimal results.

Another potential concern regarding VEGF-C therapy for patients with lymphedema or those at risk of developing the disease, is that VEGF-C is a key regulator of tumor cell growth and metastasis in a variety of solid tumors, including breast cancer. (Skobe et al., 2001; Chen et al., 2012; Kong et al., 2021) Increased VEGF-C expression increases regional lymph node and distant metastasis and is associated with decreased overall prognosis. (Hoshida et al., 2006; Lohela et al., 2009; Tammela and Alitalo, 2010) VEGF-C also promotes proliferation, migration, and invasion of epithelial breast cancer cells. (Karkkainen et al., 2001; Kong et al., 2021) Thus, the delivery of large doses of VEGF-C at the time of surgery to prevent lymphedema development may impact the oncologic aspects of patient care and requires careful study.

\section{Other Lymphangiogenic Growth Factors}

Other lymphangiogenic growth factors have also been used in preclinical models. For example, fibroblast growth factor 2 (FGF2), promotes lymphangiogenesis by inducing the expression of VEGF-C and VEGF-D. (Javerzat et al., 2002) Onishi et al. demonstrated that topical FGF2 reduces edema, increases lymphatic vessel density, improves lymphatic function (evaluated as the fluorescence intensity of indocyanine green every 3 days), and upregulates VEGF-C expression in a rat tail model of lymphedema. (Onishi et al., 2014)

Hepatocyte growth factor (HGF) regulates migration, proliferation, and differentiation of a wide variety of cells. (Nakamura et al., 1989) HGF is also a powerful promoter of lymphangiogenesis and can act directly on LECs by interacting with its high-affinity receptor-mesenchymal-epithelial transition factor (c-MET). (Kajiya et al., 2005; Cao et al., 2006; Saito et al., 2006) HGF/MET mutations have been identified in patients with primary lymphedema, and single nucleotide polymorphisms of this gene are associated with an increased risk of developing BCRL. (Finegold et al., 2008) MET somatic activating mutations have also been identified in lymphovenous malformations. (Palmieri et al., 2021) Experimental studies have also shown that HGF may have some utility in treating lymphedema. For example, weekly HGF gene therapy decreased swelling and increased lymphangiogenesis in a rat tail model of lymphedema. (Saito et al., 2006)

Retinoic acid agonists such as 9-cis retinoic acid (RA)--a metabolite of vitamin A that is FDA-approved for treating Kaposi's sarcoma and chronic eczema--increase migration and differentiation of LECs and lymphangiogenesis in vitro and 
preclinical models of lymphedema. (Choi et al., 2012; Wong, 2021) 9-cis RA treatment also effectively prevented the development of postsurgical lymphedema in a mouse hindlimb model of lymphedema by promoting the formation of collateral lymphatics by activating FGFR signaling. (Jin et al., 2012; Bramos et al., 2016; Perrault et al., 2019; Daneshgaran et al., 2020)

Despite the exciting developments in bench-to-bedside research throughout the past decade, it is important to address the gaps in current clinical trials, including relatively small patient cohorts and lack of standardized and reproducible outcome measures. These challenges and shortcomings are nicely reviewed in other manuscripts. (Forte et al., 2019f; Herantis Pharma Plc, 2021; Walker et al., 2021)

\section{ANTI-INFLAMMATORY TREATMENTS FOR LYMPHEDEMA}

\section{Innate Immune Pathways}

Inflammation is a clinical hallmark of lymphedema and a consistent finding in clinical specimens and preclinical models. However, the importance of inflammation to the pathophysiology of lymphedema has only recently been appreciated. Studies by Rockson's group highlighted the key role of inflammatory cells by showing that anti-inflammatory treatments were highly effective in preclinical models; In an important study, Dr. Rockson's group showed that lymphatic insufficiency in a mouse model of lymphedema resulted in a marked inflammatory response in the skin with a molecular signature of acute inflammation, fibrosis, and oxidative stress. (Tabibiazar et al., 2006) These studies led to an investigation on the effects of ketoprofen, a non-steroidal anti-inflammatory (NSAID) medication, in a mouse tail model of lymphedema. (Nakamura et al., 2009; Tian et al., 2017; Rockson et al., 2018) Ketoprofen is indicated to manage pain, dysmenorrhea, rheumatoid arthritis, and osteoarthritis. (Kawai et al., 2010; U.S. Prescribing information, 2021a) While it has been shown to have inhibitory effects on prostaglandin and leukotriene synthesis as well as anti-bradykinin activity, its mode of action, like that of other NSAIDs, has not been fully elucidated. (U.S. Prescribing information, 2021a)

Using a mouse-tail model, Nakamura et al. demonstrated that subcutaneous injection of ketoprofen starting on postoperative day 3 (POD 3) reduced tail volumes and epidermal thickness, decreased inflammation, and improved the histologic changes of the capillary lymphatics. (Nakamura et al., 2009) While ketoprofen treatment had broad anti-inflammatory effects, the authors also observed a paradoxical increase in the expression of inflammatory cytokines TNF- $\alpha$ and MCP-1, along with robust up-regulation of VEGF-C and VEGFR-3. The authors hypothesized that ketoprofen promoted lymphangiogenesis via TNF- $\alpha$ mediated VEGF-C up-regulation. (Nakamura et al., 2009)

The promising results of these preclinical studies have led to a clinical trial using ketoprofen in patients with either primary or secondary lymphedema of the upper or lower extremity (NCT02257970). (Rockson et al., 2018) In an exploratory portion of the trial, 21 patients with lymphedema were enrolled in an open-label trial receiving ketoprofen $75 \mathrm{mg}$ by mouth 3 times daily for 4 months (Rockson et al., 2018) Ketoprofen therapy significantly improved skin pathology as evidenced by decreased dermal thickness, collagen deposition, co intercellular mucin deposition, and perivascular inflammation compared with baseline biopsies before initiation of treatment. (Rockson et al., 2018) However, no significant differences in either limb volume or bioimpedance were demonstrated following ketoprofen treatment. (Rockson et al., 2018) In the second phase of the study, 34 patients (16 treated with ketoprofen 18 without) with the same inclusion criteria were recruited for a randomized, placebo-controlled trial. This portion of the study again demonstrated improvements in skin histology as evidenced by decreased skin thickness and decreased plasma granulocyte CSF (G-CSF) expression following Ketoprofen administration. (Rockson et al., 2018) However, treatment with ketoprofen did not significantly decrease limb volumes or bioimpedance. In addition, while treatment with ketoprofen in this study was reported to be safe with no serious adverse events, it is important to note that prolonged NSAID use is limited by a black box warning regarding cardiovascular, renal, and gastrointestinal toxicity. (FDA, 2021; U.S. Prescribing information, 2021a)

Unlike other commonly used NSAIDs, ketoprofen inhibits both the 5-lipoxygenase (5-LOX) and the cyclooxygenase (COX) pathways. (Nakamura et al., 2009) Therefore, to determine which pathway was important for the beneficial effects of ketoprofen on lymphedema, Dr. Rockson's group used a mouse model of lymphedema to analyze the efficacy of specific inhibitors of each pathway and found that the therapeutic effect of ketoprofen was attributable to the inhibition of the 5-LOX pathway metabolite leukotriene B4 $\left(\mathrm{LTB}_{4}\right)$. (Tian et al., 2017) Inhibition of $\mathrm{LTB}_{4}$ with Bestatin (Ubenimex), a selective $\mathrm{LTB}_{4}$ antagonist with no anti-COX activity, decreased swelling, and increased lymphatic function in the mouse tail model of lymphedema. Mechanistically, $\mathrm{LTB}_{4}$ had a bimodal effect on lymphangiogenesis: low doses of $\mathrm{LTB}_{4}$ increased lymphangiogenesis while high concentrations-as found in lymphedema-inhibited lymphangiogenesis. These encouraging results have led to a multicenter placebo-controlled trial of 46 lower extremity lymphedema participants who received $150 \mathrm{mg}$ bestatin 3 times daily for 6 months (NCT02700529). (ULTRA, 2021) The results of this trial are currently pending.

Interestingly, a recent study utilizing the mouse tail model of lymphedema showed that although treatment with bestatin increased lymphatic contractile activity, drug therapy did not modulate the overall leukocyte populations in the draining lymph nodes and did not decrease tail swelling. (Cribb et al., 2021) The authors suggested that addressing lymphatic vessel dysfunction is insufficient for lymphedema prevention/treatment.

\section{Adaptive Immune Pathways}

Recent studies from our lab and others have shown that $\mathrm{CD} 4^{+} \mathrm{T}$ helper (TH) cells in lymphedematous tissues play a key role in the pathophysiology of lymphedema. Using biopsy specimens from women with unilateral BCRL and mouse models of lymphedema, we have shown that the number of infiltrating $\mathrm{TH}$ cells is 
increased in lymphedematous tissues. Further, we found that increasing numbers of $\mathrm{CD}^{+}$cells are correlated with the clinical severity of the disease. (Avraham et al., 2013) Transgenic mice lacking $\mathrm{CD}^{+}$cells or mice treated with neutralizing antibodies against $\mathrm{CD}^{+}$cells did not develop lymphedema following lymphatic injury in the mouse tail model of the disease. In contrast, depletion of other inflammatory cell types such as B cells, cytotoxic $\left(\mathrm{CD}^{+}\right) \mathrm{T}$ cells, or macrophages either has no effect or worsens the pathology. (Zampell et al., 2012a; Ghanta et al., 2015; García Nores et al., 2018) Indeed, even limited numbers of $\mathrm{CD}^{+}$cells that remain after total body irradiation or adoptive transfer of $\mathrm{CD} 4^{+}$cells to $\mathrm{CD} 4$ knockout mice resulted in the development of lymphedema following skin and lymphatic resection. (Ly et al., 2019a)

\section{Tacrolimus}

Preclinical mouse lymphedema models have shown promising results when $\mathrm{T}$ cell infiltration and activation in the skin are inhibited using topical medications. (Forte et al., 2019b) Indeed, these pathologic changes share distinct similarities to other chronic skin inflammatory diseases such as atopic dermatitis that are treated with topical $\mathrm{T}$ cell inhibitors and steroids. (Brandt and Sivaprasad, 2011; James and Kwok, 2011; Su et al., 2017; Acevedo et al., 2020) Tacrolimus, a macrolide calcineurin inhibitor, exerts its anti-T-cell properties by inhibiting the Nuclear factor of activated T-cells (NFAT) signaling, ultimately decreasing IL-2 expression. Because IL2 is essential for both T-cell activation differentiation, and proliferation, Tacrolimus administration results in profound $\mathrm{CD}^{+}$cell immunosuppressive effects. (Smith, 1988; Clipstone and Crabtree, 1992; Chow et al., 1999; Rautajoki et al., 2008; Liao et al., 2013) The topical formulation is FDA-approved for treating cutaneous inflammatory conditions, including atopic dermatitis, psoriasis, and localized scleroderma. (Ruzicka et al., 1997; Mancuso and Berdondini, 2005; Wang and Lin, 2014; U.S. Prescribing information, 2021b) Topical treatment of mouse tails either before lymphedema development or once it had become established was highly effective for reducing fibroadipose tissue deposition and improving lymphatic function. (Gardenier et al., 2017) This treatment significantly decreased macrophage and $\mathrm{T}$ cell infiltration and expression of inflammatory cytokines. Importantly, topical treatments did not result in significant systemic absorption, thus mitigating the potentially toxic effects of this drug on generalized immune responses and kidney function. This concept is supported by other studies demonstrating that intermittent topical tacrolimus application for up to 1 year does not result in significant blood concentrations of the drug. (U.S. Prescribing information, 2021b) Clinical studies with periodic blood sampling in a total of 1,391 patients have confirmed this finding, demonstrating a measured blood concentration of less than $2 \mathrm{ng} / \mathrm{ml}$ in $90 \%$ of patients and 30 -fold less exposure of Tacrolimus as compared with oral administration. (U.S. Prescribing information, 2021b) Nevertheless, our group has taken a cautious approach to using Tacrolimus clinically since application of the drug to a large body surface area (e.g., an entire arm or leg) as would occur in patients with lymphedema may result in systemic absorption.

\section{TH2 Inhibition with Neutralizing Antibodies}

Naïve TH cell differentiation requires interaction and activation by antigen-presenting cells (APCs) in regional lymph nodes. Using adoptive transfer experiments with tagged leukocytes, our lab has shown that lymphatic ligation results in rapid activation of APCs in the skin distal to the zone of injury within $12 \mathrm{~h}$. These APCs migrate to regional draining lymph nodes where they interact with naive $\mathrm{CD} 4^{+}$cells to promote a mixed $\mathrm{TH} 1 / \mathrm{TH} 2$ inflammatory response and are then released into the systemic circulation. (García Nores et al., 2018) Inhibition of T cell release by the lymph node using FTY 720 $\left(\right.$ Fingolimod $\left.^{\circledR}\right)$-a sphingosine 1-phosphate receptor 1 agonist that is FDA approved for the treatment of multiple sclerosis--prevents lymphedema development in the mouse tail model of lymphedema, suggesting that $\mathrm{T}$ cell differentiation in the lymph node plays a key role in the pathophysiology of the disease. (García Nores et al., 2018; U.S. Prescribing information, 2021) Activated $\mathrm{TH}$ cells migrate back to the lymphedematous tissues via the expression of cell surface receptors that recognize their cognate ligands on inflamed blood vessels in the lymphedematous tissues. (García Nores et al., 2018)

TH cells can differentiate into various lineages such as TH1, TH2, TH17, and T-regulatory cells. (Zhu et al., 2010) We have found that $\mathrm{TH} 2$ cell differentiation is a key process in the pathophysiology of lymphedema. (Ly et al., 2019b) This concept is supported by the fact that transgenic mice with impaired TH2 differentiation potential (Stat-6 knockouts) do not develop lymphedema following skin/lymphatic ablation. In contrast, mice with impaired TH1 differentiation potential (T-bet knockouts) develop lymphedema indistinguishable from wildtype controls. (Ly et al., 2019b) Similarly, neutralizing antibody inhibition of TH2 differentiation using interleukin 4 (IL4) or IL13 - cytokines necessary for differentiation of naïve $\mathrm{CD} 4^{+}$cells to the $\mathrm{TH} 2$ lineage-is effective in both treatment and prevention of lymphedema in the mouse tail model. Mice treated in this manner have decreased fibroadipose tissue deposition, decreased inflammation, improved lymphatic collecting vessel pumping capacity, decreased lymphatic leakiness, and overall improved lymphatic function. (Zampell et al., 2012a; Avraham et al., 2013) In addition to causing extracellular matrix deposition, $\mathrm{T}$ cellderived cytokines directly affect LECs, decreasing their responsiveness to lymphangiogenic growth factors and actively inhibiting lymphangiogenesis. (Savetsky et al., 2015; Shin et al., 2015; Gardenier et al., 2017) These findings may provide a mechanistic rationale for the finding that the expression of VEGF-C is upregulated in lymphedematous tissues, yet the formation of functional collateral lymphatics is impaired in patients with lymphedema.

Our observations that inhibition of $\mathrm{TH} 2$ differentiation improved lymphedema outcomes in preclinical models led to a clinical trial to study the efficacy of IL4/IL13 neutralizing antibodies for the treatment of unilateral BCRL (NCT02494206). (Mehrara et al., 2021) Neutralizing antibodies 
TABLE 2 | Anti-inflammatory Treatments for Lymphedema.

\begin{tabular}{|c|c|c|c|}
\hline Authors & Agent & $\begin{array}{l}\text { Study Type (sample } \\
\text { size if clinical) }\end{array}$ & Outcomes \\
\hline $\begin{array}{l}\text { Nakamura et al. } \\
\text { (2009) }\end{array}$ & Ketoprofen (NSAID) & Preclinical & $\begin{array}{l}\text { Reduced tail volumes, epidermal thickness; improved histology } \\
\text { Increased expression of TNFa, MCP-1, VEGF-C, VEGFR-3 and Prox-1 }\end{array}$ \\
\hline Tian et al. (2017) & Bestatin (LTB 4 inhibitor) & Preclinical & $\begin{array}{l}\text { Reversed tail edema, dermal thickening, lymphatic dilatation, and lymphatic } \\
\text { permeability } \\
\text { Increased lymphatic transport rate }\end{array}$ \\
\hline $\begin{array}{l}\text { Rockson et al. } \\
\text { (2018) }\end{array}$ & Bestatin $\left(\mathrm{LTB}_{4}\right.$ inhibitor $)$ & $\begin{array}{l}\text { Clinical (open label trial, } n=21 \text {; placebo- } \\
\text { controlled trial, } n=34 \text { ) }\end{array}$ & $\begin{array}{l}\text { Reduced dermal thickness, collagen thickness, mucin deposition, and } \\
\text { perivascular inflammation } \\
\text { Decreased plasma G-CSF expression }\end{array}$ \\
\hline Cribb et al. (2021) & Bestatin (LTB 4 inhibitor) & Preclinical & Increased lymphatic contractility \\
\hline $\begin{array}{l}\text { Gardenier et al. } \\
(2017)\end{array}$ & $\begin{array}{l}\text { Tacrolimus ( } \mathrm{T} \text {-cell } \\
\text { proliferation inhibitor) }\end{array}$ & Preclinical & $\begin{array}{l}\text { Reduced tail volume, fibroadipose deposition, dermal backflow, T cell and } \\
\text { macrophage inflammatory response, and production of IFN-g } \\
\text { Increased collecting vessel pumping and formation of collateral lymphatics }\end{array}$ \\
\hline $\begin{array}{l}\text { Mehrara et al. } \\
(2021)\end{array}$ & $\begin{array}{l}\text { IL4/IL13 Neutralizing } \\
\text { Antibodies }\end{array}$ & Clinical $(n=9)$ & $\begin{array}{l}\text { Reduced skin stiffness, epidermal thickness, skin collagen deposition, } \\
\text { infiltration of mast cells and T cells } \\
\text { Improved QoL outcomes }\end{array}$ \\
\hline
\end{tabular}

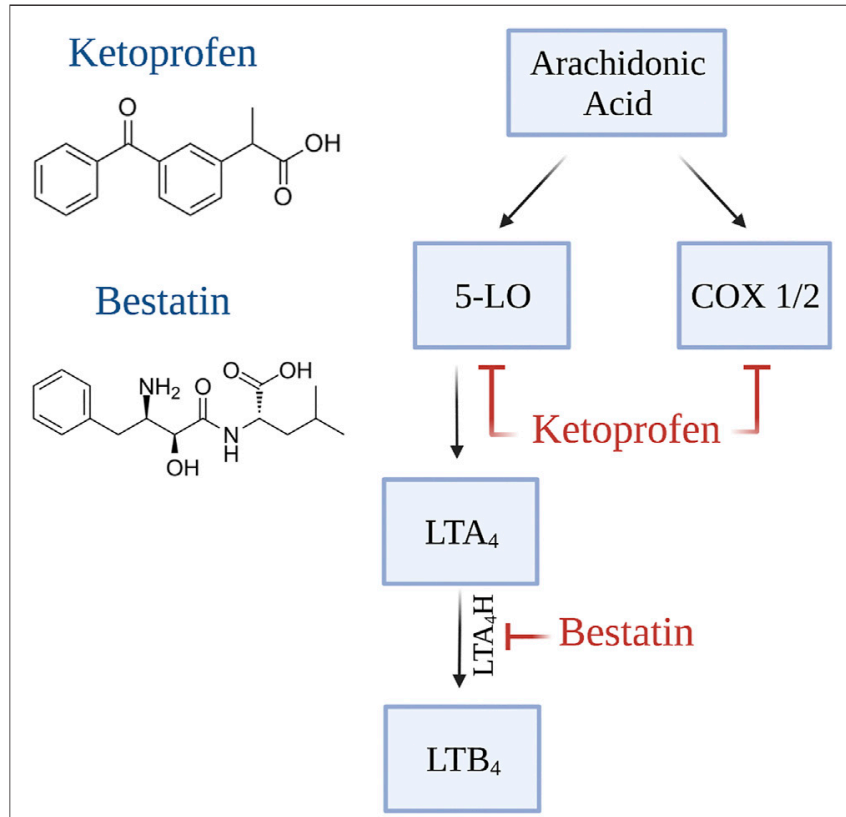

FIGURE 2 | Mechanism of action of $\mathrm{LTB}_{4}$ inhibitors (Created with BioRender).

are now commonly used to treat many chronic inflammatory diseases due to the decreased toxicity of these targeted treatments compared with traditional treatments. (Hansel et al., 2010) We recruited 9 women with stage I/II BCRL to a phase I, open-label trial utilizing QBX258, an experimental drug consisting of two humanized monoclonal antibodies that inhibit IL4 (VAK296) and IL13 (QAX576). (Mehrara et al., 2021) Patients that met the inclusion criteria were treated with once-monthly intravenous infusions of QBX258 for 4 months. (Mehrara et al., 2021) Outcomes were analyzed immediately after and 4 months following cessation of treatment. QBX258 treatment was safe, and most adverse events were minor and self-limited. Treatment with QBX258 improved QoL measurements, skin stiffness, and histologic changes in the lymphedematous limb. Drug treatment significantly decreased keratinocyte hyperplasia, mast cell infiltration, and the expression of $\mathrm{TH} 2$ inducing cytokines in the skin. However, similar to the results of the ketoprofen trials, we found no significant improvements in arm volumes or bioimpedance. Future studies with larger patient populations and more effective IL4/IL13 inhibiting compounds (e.g., Dupilmab) are needed.

\section{TH2 Inhibition with Tetracyclines}

Tetracycle antibiotics have shown promise for treating filariasis, a parasitic disease that results in the development of lymphedema due to chronic lymphatic obstruction. (Mand et al., 2012; Debrah et al., 2006; U.S. Prescribing information, 2021c) The lymphatic pathology in filariasis is primarily host-immune mediated, and lymphedema severity is closely related to the magnitude of $\mathrm{CD} 4^{+}$ T cell immune responses. (Babu et al., 2009; Babu and Nutman, 2014) Filarial infections also increase plasma levels of VEGF-C and $\mathrm{TH} 2$ cytokines, suggesting that $\mathrm{TH} 2$ adaptive immune responses also play a key role in the development of filarialinduced lymphedema. (Debrah et al., 2006)

Early reports documenting the potential for tetracyclines to treat filariasis were related to the anti-parasitic effects of the drug. (Bandi et al., 1999; Hoerauf et al., 2003) A double-blind, placebocontrolled trial of 18 patients with bancroftian filariasis in Ghana compared lymphedema in patients randomized to a 6-weeks regimen of $200 \mathrm{mg} /$ day doxycycline vs placebo (ISRCTN 14757). (Debrah et al., 2006) All patients were also treated with standard anti-parasitic treatment, and lymphedema outcomes were analyzed 12 and 24 months later. At the 1-year time point, patients treated with Doxycycline had decreased serum levels of VEGF and soluble VEGFR3. These changes correlated with a reduction in the mean stage of lymphedema as measured by improved skin texture and reduced skin folds. However, it is important to note that despite the evidence suggesting that soluble VEGFR3 is related to impaired lymphangiogenesis in preclinical models, this is the first 


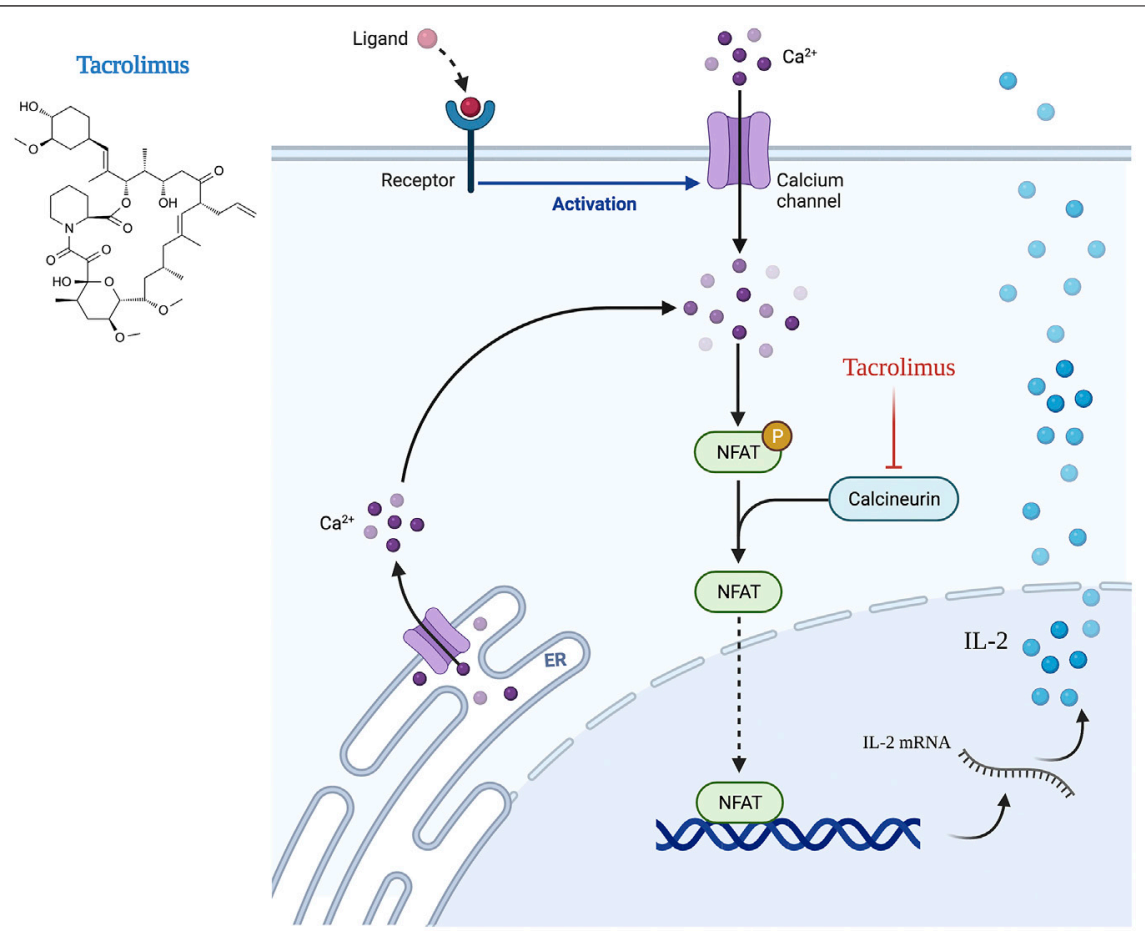

FIGURE 3 | Mechanism of action of tacrolimus (Created with BioRender).

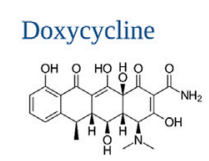

Naïve CD4+ cells

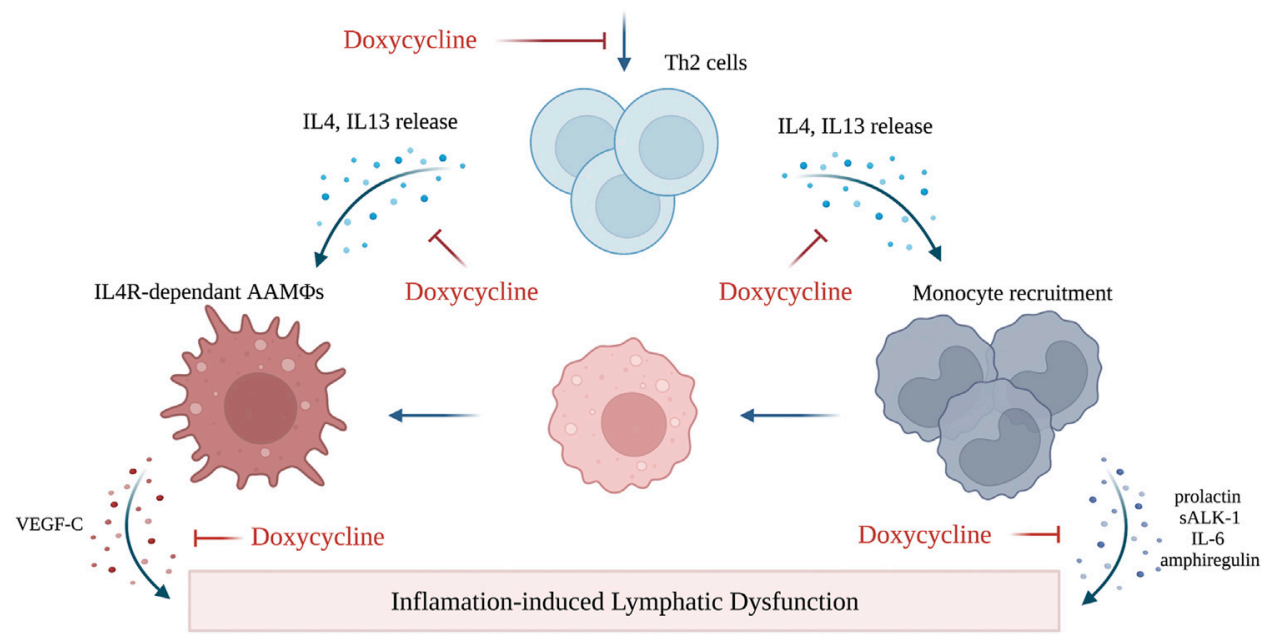

FIGURE 4 | Mechanism of action of doxycycline (created with BioRender). Adopted from: (Furlong-Silva et al., 2021).

clinical trial to utilize soluble VEGFR3 levels as a clinical outcome measure. (Mäkinen et al., 2001a) These findings led to a larger study on 162 patients with mild to moderate lymphedema randomized to 3 treatment arms comparing a 6-weeks course of treatment with amoxicillin $(1000 \mathrm{mg} / \mathrm{d})$, Doxycycline $(200 \mathrm{mg} /$ d), or placebo (ISRCTN 90861344). (Mand et al., 2012) At 1 and 2 -years follow-up, nearly $44 \%$ of patients treated with Doxycycline showed improvements in their disease status. In contrast, improvements were noted in only 3.2 and $5.6 \%$ of patients treated with amoxicillin or placebo, leading the 
authors to recommend a 6-weeks course of doxycycline treatment every year or every other year for patients with mild-to-moderate filarial lymphedema.

The finding that the beneficial effects of Doxycycline may be related to anti-inflammatory rather than anti-microbial activity-supported by the fact that Doxycycline was more effective than amoxicillin-has led to an interesting study using a mouse model of filarial lymphedema. (Furlong-Silva et al., 2021) This model, similar to the clinical scenario, was associated with impaired lymphatic function and increased circulating levels of VEGF-C. In addition, filarial-induced lymphatic dysfunction was dependent on IL-4 receptor immune responses. The study also showed that the beneficial effects of tetracycline in this model were related to decreased monocyte recruitment, inhibition of alternatively activated macrophage polarization, and decreased TH2 differentiation. (Furlong-Silva et al., 2021) With an established safety record in other inflammatory disorders, such as rheumatoid arthritis and rosacea, these findings suggest that doxycycline therapy may be a useful adjunct for the treatment of other forms of lymphedema. (Sapadin and Fleischmajer, 2006)

Despite their promising preclinical and clinical findings, the majority of clinical trials exploring the role of anti-inflammatory agents in lymphedema have many limitations (e.g., small numbers of patients, non-randomized studies, retrospective analyses, heterogenous outcome measures, etc.).

Table 2 summarizes the current knowledge regarding preclinical and clinical studies utilizing immune-based agents to treat secondary lymphedema. The mechanism of action of the pharmacological agents reviewed in this section is illustrated in Figure 2, Figure 3, Figure 4.

\section{ANTI-FIBROTIC TREATMENTS FOR LYMPHEDEMA}

Fibrosis, like inflammation, is a clinical hallmark of lymphedema. (Kataru et al., 2019) Lymphedema biopsy samples demonstrate accumulation of collagen fibers in the reticular and papillary dermis, progressive fibrosis and luminal obstruction of collecting lymphatics, and dense accumulation of collagen fibers around capillary lymphatics. (Mihara et al., 2012) Fibrosis, independent of lymphedema, is associated with decreased lymphatic function in wound healing, radiation, and obesity. (Avraham et al., 2002; Clavin et al., 2008; Zampell et al., 2012b)

Transforming growth factor beta-1 (TGF-B1) is a protein growth factor that plays an essential role in various physiologic and pathologic settings. Numerous clinical and experimental studies have implicated TGF-B1 as an important regulator of pathological fibrosis. (Meng et al., 2016) These effects

\section{REFERENCES}

Acevedo, N., Benfeitas, R., Katayama, S., Bruhn, S., Andersson, A., Wikberg, G., et al. (2020). Epigenetic Alterations in Skin Homing CD4+CLA+ T Cells of Atopic Dermatitis Patients. Sci. Rep. 10, 18020. doi:10.1038/s41598-02074798-z are related to increased fibroblast collagen deposition, decreased extracellular matrix turnover, and modulation of inflammatory response. (Meng et al., 2016) The expression of TGF-B1 is increased in clinical lymphedema specimens and mouse models of the disease, suggesting that this growth factor also plays a role in regulating lymphedema-induced fibrosis. (Sano et al., 2020) Inhibition of TGF-B1 with a small molecule inhibitor decreases fibrosis and improves radiation-induced lymphatic dysfunction. (Avraham et al., 2010) Other studies have shown that inhibition of TGF-B1 using small molecule inhibitors or neutralizing antibodies decreases fibrosis and the severity of lymphedema in the mouse tail model. (Clavin et al., 2008; Sano et al., 2020; Yoon et al., 2020)

Anti-TGF-B1 treatments also increased collateral lymphatic formation, a finding that is supported by the antilymphangiogenic activity of TGF-B1 in vitro and some physiologic settings. (Sano et al., 2020) Thus, there is significant potential for anti-fibrotic and anti-TGF-B1 therapies for lymphedema treatment. However, effective means of chronically decreasing TGF-B1 activity without induction of autoimmune responses remains a challenge and will require additional investigation.

\section{CONCLUSIONS}

The lack of a cure for lymphedema is largely related to an insufficient understanding of the pathophysiology of the disease. Advances in the last 2 decades have made important inroads in this area and have identified many potential treatment options, including lymphangiogenic cytokine delivery, anti-inflammatory medications, and antifibrotic strategies. These treatments may be used in conjunction with traditional methods of treating lymphedema or as adjuncts to surgical management. The possibility of treating lymphedema with topical medications is exciting as this approach may decrease the potential toxicity of systemic treatment. Nevertheless, additional studies with larger sample size, improved methodological quality and standardized and reproducible outcome measures are required to bring these options from the bench to the bedside.

\section{AUTHOR CONTRIBUTIONS}

$\mathrm{SB}, \mathrm{BJM}$, and RPK took the lead in writing the manuscript with input from all authors. All authors provided critical feedback and helped shape the manuscript.

Ahmadzadeh, N., Robering, J. W., Kengelbach-Weigand, A., Al-Abboodi, M., Beier, J. P., Horch, R. E., et al. (2020). Human Adipose-Derived Stem Cells Support Lymphangiogenesis In Vitro by Secretion of Lymphangiogenic Factors. Exp. Cel Res 388, 111816. doi:10.1016/j.yexcr.2020.111816

Allam, O., Park, K. E., Chandler, L., Mozaffari, M. A., Ahmad, M., Lu, X., et al. (2020). The Impact of Radiation on Lymphedema: a Review of the Literature. Gland Surg. 9, 596-602. doi:10.21037/gs.2020.03.20 
Avraham, T., Yan, A., Zampell, J. C., Daluvoy, S. V., Haimovitz-Friedman, A., Cordeiro, A. P., et al. (2010). Radiation Therapy Causes Loss of Dermal Lymphatic Vessels and Interferes with Lymphatic Function by TGF-Beta1Mediated Tissue Fibrosis. Am. J. Physiol. Cel Physiol 299, C589-C605. doi:10. 1152/ajpcell.00535.2009

Avraham, T., Zampell, J. C., Yan, A., Elhadad, S., Weitman, E. S., Rockson, S. G., et al. (2013). Th2 Differentiation Is Necessary for Soft Tissue Fibrosis and Lymphatic Dysfunction Resulting from Lymphedema. Faseb j 27, 1114-1126. doi:10.1096/fj.12-222695

Avraham, T., Clavin, N. W., Daluvoy, S. V., Fernandez, J., Soares, M. A., Cordeiro, A. P., et al. (2002). Fibrosis Is a Key Inhibitor of Lymphatic Regeneration. Plast. Reconstr. Surg. 124, 438-450. doi:10.1097/PRS.0b013e3181adcf4b

Babu, S., Bhat, S. Q., Pavan Kumar, N., Lipira, A. B., Kumar, S., Karthik, C., et al. (2009). Filarial Lymphedema Is Characterized by Antigen-specific Th1 and Th17 Proinflammatory Responses and a Lack of Regulatory T Cells. Plos Negl. Trop. Dis. 3, e420. doi:10.1371/journal.pntd.0000420

Babu, S., and Nutman, T. B. (2014). Immunology of Lymphatic Filariasis. Parasite Immunol. 36, 338-346. doi:10.1111/pim.12081

Baden, L. R., El Sahly, H. M., Kotloff, K., Frey, S., Novak, R., Diemert, D., et al. (2021). Efficacy and Safety of the mRNA-1273 SARS-CoV-2 Vaccine. N. Engl. J. Med. 384, 403-416. doi:10.1056/NEJMoa2035389

Badger, C., Preston, N., Seers, K., and Mortimer, P. (2004). Benzo-pyrones for Reducing and Controlling Lymphoedema of the Limbs. Cochrane Database Syst. Rev. 2004 (2), CD003140. doi:10.1002/14651858.CD003140.pub2

Badger, C., Seers, K., Preston, N., and Mortimer, P. (2004). Antibiotics/Antiinflammatories for Reducing Acute Inflammatory Episodes in Lymphoedema of the Limbs. Cochrane database Syst. Rev. doi:10.1002/14651858.cd003143. pub2 Available at: https://libguides.jcu.edu.au/ama10th/articles/cochranereview

Bandi, C., McCall, J. W., Genchi, C., Corona, S., Venco, L., and Sacchi, L. (1999). Effects of Tetracycline on the Filarial Worms Brugia Pahangi and Dirofilaria Immitis and Their Bacterial Endosymbionts Wolbachia. Int. J. Parasitol. 29, 357-364. doi:10.1016/s0020-7519(98)00200-8

Barufi, S., Pereira de Godoy, H. J., Pereira de Godoy, J. M., and Guerreiro Godoy, M. F. (2021). Exercising and Compression Mechanism in the Treatment of Lymphedema. Cureus 13, e16121. doi:10.7759/cureus.16121

Beaulac, S. M., McNair, L. A., Scott, T. E., LaMorte, W. W., and Kavanah, M. T. (2002). Lymphedema and Quality of Life in Survivors of Early-Stage Breast Cancer. Arch. Surg. 137, 1253-1257. doi:10.1001/archsurg.137.11. 1253

Bramos, A., Perrault, D., Yang, S., Jung, E., Hong, Y. K., and Wong, A. K. (2016). Prevention of Postsurgical Lymphedema by 9-cis Retinoic Acid. Ann. Surg. 264, 353-361. doi:10.1097/SLA.0000000000001525

Brandt, E. B., and Sivaprasad, U. (2011). Th2 Cytokines and Atopic Dermatitis. J. Clin. Cel Immunol 2, 110. doi:10.4172/2155-9899.1000110

Brown, S., Brown, T., Cederna, P. S., and Rohrich, R. J. (2020). The Race for a COVID-19 Vaccine: Current Trials, Novel Technologies, and Future Directions. Plast. Reconstr. Surg. Glob. Open 8, e3206. doi:10.1097/GOX. 0000000000003206

Cao, R., Björndahl, M. A., Gallego, M. I., Chen, S., Religa, P., Hansen, A. J., et al. (2006). Hepatocyte Growth Factor Is a Lymphangiogenic Factor with an Indirect Mechanism of Action. Blood 107, 3531-3536. doi:10.1182/blood2005-06-2538

Carl, H. M., Walia, G., Bello, R., Clarke-Pearson, E., Hassanein, A. H., Cho, B., et al. (2017). Systematic Review of the Surgical Treatment of Extremity Lymphedema. J. Reconstr. Microsurg 33, 412-425. doi:10.1055/s-0037-1599100

Chen, J. C., Chang, Y. W., Hong, C. C., Yu, Y. H., and Su, J. L. (2012). The Role of the VEGF-C/VEGFRs axis in Tumor Progression and Therapy. Int. J. Mol. Sci. 14, 88-107. doi:10.3390/ijms14010088

Cheung, L., Han, J., Beilhack, A., Joshi, S., Wilburn, P., Dua, A., et al. (2006). An Experimental Model for the Study of Lymphedema and its Response to Therapeutic Lymphangiogenesis. BioDrugs 20, 363-370. doi:10.2165/ 00063030-200620060-00007

Choi, I., Lee, S., Kyoung Chung, H., Suk Lee, Y., Eui Kim, K., Choi, D., et al. (2012). 9-cis Retinoic Acid Promotes Lymphangiogenesis and Enhances Lymphatic Vessel Regeneration: Therapeutic Implications of 9-cis Retinoic Acid for Secondary Lymphedema. Circulation 125, 872-882. doi:10.1161/ CIRCULATIONAHA.111.030296
Chow, C. W., Rincón, M., and Davis, R. J. (1999). Requirement for Transcription Factor NFAT in Interleukin-2 Expression. Mol. Cel Biol 19, 2300-2307. doi:10. $1128 /$ mcb.19.3.2300

Clavin, N. W., Avraham, T., Fernandez, J., Daluvoy, S. V., Soares, M. A., Chaudhry, A., et al. (2008). TGF-betal Is a Negative Regulator of Lymphatic Regeneration during Wound Repair. Am. J. Physiol. Heart Circ. Physiol. 295, H2113-H2127. doi:10.1152/ajpheart.00879.2008

Clipstone, N. A., and Crabtree, G. R. (1992). Identification of Calcineurin as a Key Signalling Enzyme in T-Lymphocyte Activation. Nature 357, 695-697. doi:10. 1038/357695a0

Connell, F. C., Gordon, K., Brice, G., Keeley, V., Jeffery, S., Mortimer, P. S., et al. (2013). The Classification and Diagnostic Algorithm for Primary Lymphatic Dysplasia: an Update from 2010 to Include Molecular Findings. Clin. Genet. 84, 303-314. doi:10.1111/cge.12173

Conrad, C., Niess, H., Huss, R., Huber, S., von Luettichau, I., Nelson, P. J., et al. (2009). Multipotent Mesenchymal Stem Cells Acquire a Lymphendothelial Phenotype and Enhance Lymphatic Regeneration In Vivo. Circulation 119, 281-289. doi:10.1161/CIRCULATIONAHA.108.793208

Cormier, J. N., Askew, R. L., Mungovan, K. S., Xing, Y., Ross, M. I., and Armer, J. M. (2010). Lymphedema beyond Breast Cancer: a Systematic Review and MetaAnalysis of Cancer-Related Secondary Lymphedema. Cancer 116, 5138-5149. doi:10.1002/cncr.25458

Cowher, M. S., Grobmyer, S. R., Lyons, J., O’Rourke, C., Baynes, D., and Crowe, J. P. (2014). Conservative Axillary Surgery in Breast Cancer Patients Undergoing Mastectomy: Long-Term Results. J. Am. Coll. Surg. 218, 819-824. doi:10.1016/j.jamcollsurg.2013.12.041

Cribb, M. T., Sestito, L. F., Rockson, S. G., Nicolls, M. R., Thomas, S. N., and Dixon, J. B. (2021). The Kinetics of Lymphatic Dysfunction and Leukocyte Expansion in the Draining Lymph Node during LTB4 Antagonism in a Mouse Model of Lymphedema. Int. J. Mol. Sci. 22, 4455. doi:10.3390/ijms22094455

Daneshgaran, G., Paik, C. B., Cooper, M. N., Sung, C., Lo, A., Jiao, W., et al. (2020). Prevention of Postsurgical Lymphedema via Immediate Delivery of SustainedRelease 9-cis Retinoic Acid to the Lymphedenectomy Site. J. Surg. Oncol. 121, 100-108. doi:10.1002/jso.25587

Danielle, H., Rochlin, M. P., and Nguyen, D. H. (2019). Nanofibrillar Collagen Scaffold Implantation Enhances Lymphatic Regeneration in Conjunction with Lymphatic Venous Anastomosis or Vascularized Lymph Node Transfer. Taouan, Taiwan: World Society for Lymphedema Surgery-WSLS. Available at: http:// www.lymphedema-surgery.org/2019\%20WSLS\%20Free\%20Paper/2019_ WSLS_Free_Paper_003.pdf (Accessed November 15, 2021)

Dayan, J. H., Ly, C. L., Kataru, R. P., and Mehrara, B. J. (2018). Lymphedema: Pathogenesis and Novel Therapies. Annu. Rev. Med. 69, 263-276. doi:10.1146/ annurev-med-060116-022900

De Vrieze, T., Nevelsteen, I., Thomis, S., De Groef, A., Tjalma, W. A. A., Gebruers, N., et al. (2020). What Are the Economic burden and Costs Associated with the Treatment of Breast Cancer-Related Lymphoedema? A Systematic Review. Support Care Cancer 28, 439-449. doi:10.1007/s00520-019-05101-8

Debrah, A. Y., Mand, S., Specht, S., Marfo-Debrekyei, Y., Batsa, L., Pfarr, K., et al. (2006). Doxycycline Reduces Plasma VEGF-C/sVEGFR-3 and Improves Pathology in Lymphatic Filariasis. Plos Pathog. 2, e92. doi:10.1371/journal. ppat.0020092

DiSipio, T., Rye, S., Newman, B., and Hayes, S. (2013). Incidence of Unilateral Arm Lymphoedema after Breast Cancer: a Systematic Review and Meta-Analysis. Lancet Oncol. 14, 500-515. doi:10.1016/S1470-2045(13)70076-7

FDA (2021). U. S. F. a. D. A. FDA Drug Safety Communication: FDA Strengthens Warning that Non-aspirin Nonsteroidal Anti-inflammatory Drugs (NSAIDs) Can Cause Heart Attacks or Strokes. Available at: https://www.fda.gov/drugs/ drug-safety-and-availability/fda-drug-safety-communication-fda-strengthenswarning-non-aspirin-nonsteroidal-anti-inflammatory (Accessed December 25, 2021).

Finegold, D. N., Baty, C. J., Knickelbein, K. Z., Perschke, S., Noon, S. E., Campbell, D., et al. (2012). Connexin 47 Mutations Increase Risk for Secondary Lymphedema Following Breast Cancer Treatment. Clin. Cancer Res. 18, 2382-2390. doi:10.1158/1078-0432.CCR-11-2303

Finegold, D. N., Schacht, V., Kimak, M. A., Lawrence, E. C., Foeldi, E., Karlsson, J. M., et al. (2008). HGF and MET Mutations in Primary and Secondary Lymphedema. Lymphat Res. Biol. 6, 65-68. doi:10.1089/lrb. 2008.1524 
Forte, A. J., Boczar, D., Huayllani, M. T., Bagaria, S., and McLaughlin, S. A. (2019). Use of Autologous Blood Components in Lymphedema Treatment: A Systematic Review. Cureus 11, e5638. doi:10.7759/cureus. 5638

Forte, A. J., Boczar, D., Huayllani, M. T., Cinotto, G. J., and McLaughlin, S. (2019). Targeted Therapies in Surgical Treatment of Lymphedema: A Systematic Review. Cureus 11, e5397. doi:10.7759/cureus.5397

Forte, A. J., Boczar, D., Huayllani, M. T., Lu, X., and Ciudad, P. (2019). Lymphoscintigraphy for Evaluation of Lymphedema Treatment: A Systematic Review. Cureus 11, e6363. doi:10.7759/cureus.6363

Forte, A. J., Boczar, D., Huayllani, M. T., Lu, X., and McLaughlin, S. A. (2019). Pharmacotherapy Agents in Lymphedema Treatment: A Systematic Review. Cureus 11, e6300. doi:10.7759/cureus.6300

Forte, A. J., Boczar, D., Huayllani, M. T., McLaughlin, S. A., and Bagaria, S. (2019). Topical Approach to Delivering Targeted Therapies in Lymphedema Treatment: A Systematic Review. Cureus 11, e6269. doi:10.7759/cureus.6269

Forte, A. J., Boczar, D., Huayllani, M. T., McLaughlin, S. A., and Bagaria, S. (2019). Use of Gene Transfer Vectors in Lymphedema Treatment: A Systematic Review. Cureus 11, e5887. doi:10.7759/cureus.5887

Furlong-Silva, J., Cross, S. D., Marriott, A. E., Pionnier, N., Archer, J., Steven, A., et al. (2021). Tetracyclines Improve Experimental Lymphatic Filariasis Pathology by Disrupting Interleukin-4 Receptor-Mediated Lymphangiogenesis. J. Clin. Invest. 131, e140853. doi:10.1172/JCI140853

García Nores, G. D., Cuzzone, D. A., Kataru, R. P., Hespe, G. E., Torrisi, J. S., Huang, J. J., et al. (2018). CD4+ T Cells Are Activated in Regional Lymph Nodes and Migrate to Skin to Initiate Lymphedema. Nat. Commun. 9, 1970. doi:10. 1038/s41467-018-04418-y

Gardenier, J. C., Kataru, R. P., Hespe, G. E., Savetsky, I. L., Torrisi, J. S., Nores, G. D., et al. (2017). Topical Tacrolimus for the Treatment of Secondary Lymphedema. Nat. Commun. 8, 14345. doi:10.1038/ncomms14345

Ghalamkarpour, A., Holnthoner, W., Saharinen, P., Boon, L. M., Mulliken, J. B., Alitalo, K., et al. (2009). Recessive Primary Congenital Lymphoedema Caused by a VEGFR3 Mutation. J. Med. Genet. 46, 399-404. doi:10.1136/jmg.2008. 064469

Ghanta, S., Cuzzone, D. A., Torrisi, J. S., Albano, N. J., Joseph, W. J., Savetsky, I. L., et al. (2015). Regulation of Inflammation and Fibrosis by Macrophages in Lymphedema. Am. J. Physiol. Heart Circ. Physiol. 308, H1065-H1077. doi:10. 1152/ajpheart.00598.2014

Goldman, J., Le, T. X., Skobe, M., and Swartz, M. A. (2005). Overexpression of VEGF-C Causes Transient Lymphatic Hyperplasia but Not Increased Lymphangiogenesis in Regenerating Skin. Circ. Res. 96, 1193-1199. doi:10. 1161/01.RES.0000168918.27576.78

Gousopoulos, E., Proulx, S. T., Bachmann, S. B., Dieterich, L. C., Scholl, J., Karaman, S., et al. (2017). An Important Role of VEGF-C in Promoting Lymphedema Development. J. Invest. Dermatol. 137, 1995-2004. doi:10. 1016/j.jid.2017.04.033

Greene, A. K., and Goss, J. A. (2018). Diagnosis and Staging of Lymphedema. Semin. Plast. Surg. 32, 12-16. doi:10.1055/s-0038-1635117

Guliyeva, G., Huayllani, M. T., Boczar, D., Avila, F. R., and Forte, A. J. (2021). Correlation of Older Age with Severity of Lymphedema in Breast Cancer Survivors: A Systematic Review. Breast Dis. 40, 191-197. doi:10.3233/BD201067

Hadamitzky, C., Zaitseva, T. S., Bazalova-Carter, M., Paukshto, M. V., Hou, L., Strassberg, Z., et al. (2016). Aligned Nanofibrillar Collagen Scaffolds - Guiding Lymphangiogenesis for Treatment of Acquired Lymphedema. Biomaterials 102, 259-267. doi:10.1016/j.biomaterials.2016.05.040

Haiko, P., Makinen, T., Keskitalo, S., Taipale, J., Karkkainen, M. J., Baldwin, M. E., et al. (2008). Deletion of Vascular Endothelial Growth Factor C (VEGF-C) and VEGF-D Is Not Equivalent to VEGF Receptor 3 Deletion in Mouse Embryos. Mol. Cel Biol 28, 4843-4850. doi:10.1128/MCB.02214-07

Hansel, T. T., Kropshofer, H., Singer, T., Mitchell, J. A., and George, A. J. (2010). The Safety and Side Effects of Monoclonal Antibodies. Nat. Rev. Drug Discov. 9, 325-338. doi:10.1038/nrd3003

Hartiala, P., Suominen, S., Suominen, E., Kaartinen, I., Kiiski, J., Viitanen, T., et al. (2020). Phase 1 Lymfactin $\circledast$ Study: Short-Term Safety of Combined Adenoviral VEGF-C and Lymph Node Transfer Treatment for Upper
Extremity Lymphedema. J. Plast. Reconstr. Aesthet. Surg. 73, 1612-1621. doi:10.1016/j.bjps.2020.05.009

Hartiala, P., Lahdenperä, O., Vuolanto, A., and Saarikko, A. (2020). Abstract OT1-06-01: Lymfactin, an Investigational Adenoviral Gene Therapy Expressing VEGF-C, Is Currently Studied in a Double-Blind, Randomized, Placebo-Controlled, Multicenter, Phase 2 Clinical Study in Patients Suffering from Breast Cancer Associated Secondary Lymphedema (BCAL). Cancer Res. 80. OT1-06-01-OT01-06-01. doi:10.1158/1538-7445. sabcs19-ot1-06-01

Heiney, S. P., McWayne, J., Cunningham, J. E., Hazlett, L. J., Parrish, R. S., Bryant, L. H., et al. (2007). Quality of Life and Lymphedema Following Breast Cancer. Lymphology 40, 177-184.

Herantis Pharma Plc (2021). Herantis Announces Inconclusive Results from Phase II Study with Lymfactin in Breast Cancer Related Lymphedema ${ }^{\circledR}$. Available at: https://herantis.com/press-releases/herantis-announces-inconclusive-resultsfrom-phase-ii-study-with-lymfactin-in-breast-cancer-related-lymphedema/ (Accessed November 8, 2021).

Hoerauf, A., Mand, S., Fischer, K., Kruppa, T., Marfo-Debrekyei, Y., Debrah, A. Y., et al. (2003). Doxycycline as a Novel Strategy against Bancroftian FilariasisDepletion of Wolbachia Endosymbionts from Wuchereria Bancrofti and Stop of Microfilaria Production. Med. Microbiol. Immunol. 192, 211-216. doi:10. 1007/s00430-002-0174-6

Honkonen, K. M., Visuri, M. T., Tervala, T. V., Halonen, P. J., Koivisto, M., Lähteenvuo, M. T., et al. (2013). Lymph Node Transfer and Perinodal Lymphatic Growth Factor Treatment for Lymphedema. Ann. Surg. 257, 961-967. doi:10.1097/SLA.0b013e31826ed043

Hoshida, T., Isaka, N., Hagendoorn, J., di Tomaso, E., Chen, Y. L., Pytowski, B., et al. (2006). Imaging Steps of Lymphatic Metastasis Reveals that Vascular Endothelial Growth Factor-C Increases Metastasis by Increasing Delivery of Cancer Cells to Lymph Nodes: Therapeutic Implications. Cancer Res. 66, 8065-8075. doi:10.1158/0008-5472.CAN-06-1392

Huang, J. J., Gardenier, J. C., Hespe, G. E., García Nores, G. D., Kataru, R. P., Ly, C. L., et al. (2016). Lymph Node Transplantation Decreases Swelling and Restores Immune Responses in a Transgenic Model of Lymphedema. PloS one 11, e0168259. doi:10.1371/journal.pone.0168259

Hwang, J. H., Kim, I. G., Lee, J. Y., Piao, S., Lee, D. S., Lee, T. S., et al. (2011). Therapeutic Lymphangiogenesis Using Stem Cell and VEGF-C Hydrogel. Biomaterials 32, 4415-4423. doi:10.1016/j.biomaterials.2011.02.051

James, E. A., and Kwok, W. W. (2011). Autoreactive CD4(+) T Cells in Patients with Atopic Dermatitis. J. Allergy Clin. Immunol. 128, 100-101. doi:10.1016/j. jaci.2011.05.005

Javerzat, S., Auguste, P., and Bikfalvi, A. (2002). The Role of Fibroblast Growth Factors in Vascular Development. Trends Mol. Med. 8, 483-489. doi:10.1016/ s1471-4914(02)02394-8

Jensen, M. R., Simonsen, L., Karlsmark, T., Lanng, C., and Bülow, J. (2015). Higher Vascular Endothelial Growth Factor-C Concentration in Plasma Is Associated with Increased Forearm Capillary Filtration Capacity in Breast Cancer-Related Lymphedema. Physiol. Rep. 3, e12403. doi:10.14814/phy2.12403

Jin, D. P., An, A., Liu, J., Nakamura, K., and Rockson, S. G. (2009). Therapeutic Responses to Exogenous VEGF-C Administration in Experimental Lymphedema: Immunohistochemical and Molecular Characterization. Lymphat Res. Biol. 7, 47-57. doi:10.1089/lrb.2009.0002

Jin, M., Yu, Y., Qi, H., Xie, Y., Su, N., Wang, X., et al. (2012). A Novel FGFR3Binding Peptide Inhibits FGFR3 Signaling and Reverses the Lethal Phenotype of Mice Mimicking Human Thanatophoric Dysplasia. Hum. Mol. Genet. 21, 5443-5455. doi: $10.1093 / \mathrm{hmg} / \mathrm{dds} 390$

Jung, S. G., Im, S. H., Kim, M., Choi, M. C., Joo, W. D., Song, S. H., et al. (2021). The Association between the Number of Retrieved Pelvic Lymph Nodes and Ipsilateral Lower Limb Lymphedema in Patients with Gynecologic Cancer. J. Invest. Surg. Online ahead of print. doi:10.1080/08941939.2021.1980160

Kajiya, K., Hirakawa, S., Ma, B., Drinnenberg, I., and Detmar, M. (2005). Hepatocyte Growth Factor Promotes Lymphatic Vessel Formation and Function. EMBO J. 24, 2885-2895. doi:10.1038/sj.emboj.7600763

Karkkainen, M. J., Saaristo, A., Jussila, L., Karila, K. A., Lawrence, E. C., Pajusola, K., et al. (2001). A Model for Gene Therapy of Human Hereditary Lymphedema. Proc. Natl. Acad. Sci. U S A. 98, 12677-12682. doi:10.1073/ pnas. 221449198 
Kataru, R. P., Kim, H., Jang, C., Choi, D. K., Koh, B. I., Kim, M., et al. (2011). T Lymphocytes Negatively Regulate Lymph Node Lymphatic Vessel Formation. Immunity 34, 96-107. doi:10.1016/j.immuni.2010.12.016

Kataru, R. P., Wiser, I., Baik, J. E., Park, H. J., Rehal, S., Shin, J. Y., et al. (2019). Fibrosis and Secondary Lymphedema: Chicken or Egg. Transl Res. 209, 68-76. doi:10.1016/j.trsl.2019.04.001

Kawai, S., Uchida, E., Kondo, M., Ohno, S., Obata, J., Nawata, Y., et al. (2010). Efficacy and Safety of Ketoprofen Patch in Patients with Rheumatoid Arthritis: a Randomized, Double-Blind, Placebo-Controlled Study. J. Clin. Pharmacol. 50, 1171-1179. doi:10.1177/0091270009355813

Kayıran, O., De La Cruz, C., Tane, K., and Soran, A. (2017). Lymphedema: From Diagnosis to Treatment. Turk J. Surg. 33, 51-57. doi:10.5152/turkjsurg.2017.3870

Keith, L., Rowsemitt, C., and Richards, L. G. (2020). Lifestyle Modification Group for Lymphedema and Obesity Results in Significant Health Outcomes. Am. J. Lifestyle Med. 14, 420-428. doi:10.1177/1559827617742108

Kim, I. G., Lee, J. Y., Lee, D. S., Kwon, J. Y., and Hwang, J. H. (2013). Extracorporeal Shock Wave Therapy Combined with Vascular Endothelial Growth Factor-C Hydrogel for Lymphangiogenesis. J. Vasc. Res. 50, 124-133. doi:10.1159/ 000343699

Klein, S. L., and Flanagan, K. L. (2016). Sex Differences in Immune Responses. Nat. Rev. Immunol. 16, 626-638. doi:10.1038/nri.2016.90

Kong, D., Zhou, H., Neelakantan, D., Hughes, C. J., Hsu, J. Y., Srinivasan, R. R., et al. (2021). VEGF-C Mediates Tumor Growth and Metastasis through Promoting EMT-Epithelial Breast Cancer Cell Crosstalk. Oncogene 40, 964-979. doi:10.1038/s41388-020-01539-x

Lahdenranta, J., Hagendoorn, J., Padera, T. P., Hoshida, T., Nelson, G., Kashiwagi, S., et al. (2009). Endothelial Nitric Oxide Synthase Mediates Lymphangiogenesis and Lymphatic Metastasis. Cancer Res. 69, 2801-2808. doi:10.1158/0008-5472.CAN-08-4051

Lähteenvuo, M., Honkonen, K., Tervala, T., Tammela, T., Suominen, E., Lähteenvuo, J., et al. (2011). Growth Factor Therapy and Autologous Lymph Node Transfer in Lymphedema. Circulation 123, 613-620. doi:10. 1161/CIRCULATIONAHA.110.965384

Lai, C. M., Lai, Y. K., and Rakoczy, P. E. (2002). Adenovirus and AdenoAssociated Virus Vectors. DNA Cel Biol 21, 895-913. doi:10.1089/ 104454902762053855

Lee, M. J., Beith, J., Ward, L., and Kilbreath, S. (2014). Lymphedema Following Taxane-Based Chemotherapy in Women with Early Breast Cancer. Lymphat Res. Biol. 12, 282-288. doi:10.1089/lrb.2014.0030

Li, C. Y., Kataru, R. P., and Mehrara, B. J. (2020). Histopathologic Features of Lymphedema: a Molecular Review. Int. J. Mol. Sci. 21, 2546. doi:10.3390/ ijms21072546

Li, C. Y., Kataru, R. P., and Mehrara, B. J. (2020). Histopathologic Features of Lymphedema: A Molecular Review. Int. J. Mol. Sci. 21 (7), 2546. doi:10.3390/ ijms 21072546

Liao, W., Lin, J. X., and Leonard, W. J. (2013). Interleukin-2 at the Crossroads of Effector Responses, Tolerance, and Immunotherapy. Immunity 38, 13-25. doi:10.1016/j.immuni.2013.01.004

Liu, Y., Fang, Y., Dong, P., Gao, J., Liu, R., Hhahbaz, M., et al. (2008). Effect of Vascular Endothelial Growth Factor C (VEGF-C) Gene Transfer in Rat Model of Secondary Lymphedema. Vascul Pharmacol. 48, 150-156. doi:10.1016/j.vph. 2008.01.010

Lohela, M., Bry, M., Tammela, T., and Alitalo, K. (2009). VEGFs and Receptors Involved in Angiogenesis versus Lymphangiogenesis. Curr. Opin. Cel Biol 21, 154-165. doi:10.1016/j.ceb.2008.12.012

Ly, C. L., Cuzzone, D. A., Kataru, R. P., and Mehrara, B. J. (2019). Small Numbers of CD4+ T Cells Can Induce Development of Lymphedema. Plast. Reconstr. Surg. 143, 518e-526e. doi:10.1097/PRS.0000000000005322

Ly, C. L., Nores, G. D. G., Kataru, R. P., and Mehrara, B. J. (2019). T Helper 2 Differentiation Is Necessary for Development of Lymphedema. Transl Res. 206, 57-70. doi:10.1016/j.trsl.2018.12.003

Magadum, A., Kaur, K., and Zangi, L. (2019). mRNA-Based Protein Replacement Therapy for the Heart. Mol. Ther. 27, 785-793. doi:10.1016/j.ymthe.2018. 11.018

Mäkinen, T., Jussila, L., Veikkola, T., Karpanen, T., Kettunen, M. I., Pulkkanen, K. J., et al. (2001). Inhibition of Lymphangiogenesis with Resulting Lymphedema in Transgenic Mice Expressing Soluble VEGF Receptor-3. Nat. Med. 7, 199-205. doi:10.1038/84651
Mäkinen, T., Veikkola, T., Mustjoki, S., Karpanen, T., Catimel, B., Nice, E. C., et al. (2001). Isolated Lymphatic Endothelial Cells Transduce Growth, Survival and Migratory Signals via the VEGF-C/D Receptor VEGFR-3. EMBO J. 20, 4762-4773. doi:10.1093/emboj/20.17.4762

Mancuso, G., and Berdondini, R. M. (2005). Localized Scleroderma: Response to Occlusive Treatment with Tacrolimus Ointment. Br. J. Dermatol. 152, 180-182. doi:10.1111/j.1365-2133.2004.06318.x

Mand, S., Debrah, A. Y., Klarmann, U., Batsa, L., Marfo-Debrekyei, Y., Kwarteng, A., et al. (2012). Doxycycline Improves Filarial Lymphedema Independent of Active Filarial Infection: a Randomized Controlled Trial. Clin. Infect. Dis. 55, 621-630. doi:10.1093/cid/cis486

Mehrara, B. J., and Greene, A. K. (2014). Lymphedema and Obesity: Is There a Link. Plast. Reconstr. Surg. 134, 154e-160e. doi:10.1097/PRS.0000000000000268

Mehrara, B. J., Park, H. J., Kataru, R. P., Bromberg, J., Coriddi, M., Baik, J. E., et al. (2021). Pilot Study of Anti-th2 Immunotherapy for the Treatment of Breast Cancer-Related Upper Extremity Lymphedema. Biology (Basel) 10, 934. doi:10. 3390/biology10090934

Meng, X. M., Nikolic-Paterson, D. J., and Lan, H. Y. (2016). TGF- $\beta$ : the Master Regulator of Fibrosis. Nat. Rev. Nephrol. 12, 325-338. doi:10.1038/nrneph.2016.48

Miaskowski, C., Dodd, M., Paul, S. M., West, C., Hamolsky, D., Abrams, G., et al. (2013). Lymphatic and Angiogenic Candidate Genes Predict the Development of Secondary Lymphedema Following Breast Cancer Surgery. PloS one 8, e60164. doi:10.1371/journal.pone.0060164

Mihara, M., Hara, H., Hayashi, Y., Narushima, M., Yamamoto, T., Todokoro, T., et al. (2012). Pathological Steps of Cancer-Related Lymphedema: Histological Changes in the Collecting Lymphatic Vessels after Lymphadenectomy. PloS one 7, e41126. doi:10.1371/journal.pone.0041126

Morfoisse, F., Zamora, A., Marchaud, E., Nougue, M., Diallo, L. H., David, F., et al. (2021). Sex Hormones in Lymphedema. Cancers 13, 530. doi:10.3390/ cancers 13030530

Nakamura, K., Radhakrishnan, K., Wong, Y. M., and Rockson, S. G. (2009). Antiinflammatory Pharmacotherapy with Ketoprofen Ameliorates Experimental Lymphatic Vascular Insufficiency in Mice. PloS one 4, e8380. doi:10.1371/ journal.pone.0008380

Nakamura, T., Nishizawa, T., Hagiya, M., Seki, T., Shimonishi, M., Sugimura, A., et al. (1989). Molecular Cloning and Expression of Human Hepatocyte Growth Factor. Nature 342, 440-443. doi:10.1038/342440a0

Nguyen, D. H., Zhou, A., Posternak, V., and Rochlin, D. H. (2021). Nanofibrillar Collagen Scaffold Enhances Edema Reduction and Formation of New Lymphatic Collectors after Lymphedema Surgery. Plast. Reconstr. Surg. 148 (6), 1382-1393. doi:10.1097/prs.0000000000008590

Nguyen, D., Zaitseva, T. S., Zhou, A., Rochlin, D., Sue, G., Deptula, P., et al. (2021). Lymphatic Regeneration after Implantation of Aligned Nanofibrillar Collagen Scaffolds: Preliminary Preclinical and Clinical Results. J. Surg. Oncol. 2, 113-122. doi:10.1002/jso.26679

Ogata, F., Fujiu, K., Matsumoto, S., Nakayama, Y., Shibata, M., Oike, Y., et al. (2016). Excess Lymphangiogenesis Cooperatively Induced by Macrophages and CD4(+) T Cells Drives the Pathogenesis of Lymphedema. J. Invest. Dermatol. 136, 706-714. doi:10.1016/j.jid.2015.12.001

Oh, S. J., Jeltsch, M. M., Birkenhäger, R., McCarthy, J. E., Weich, H. A., Christ, B., et al. (1997). VEGF and VEGF-C: Specific Induction of Angiogenesis and Lymphangiogenesis in the Differentiated Avian Chorioallantoic Membrane. Dev. Biol. 188, 96-109. doi:10.1006/dbio.1997.8639

Oliver, G. (2004). Lymphatic Vasculature Development. Nat. Rev. Immunol. 4, 35-45. doi:10.1038/nri1258

Olsson, A. K., Dimberg, A., Kreuger, J., and Claesson-Welsh, L. (2006). VEGF Receptor Signalling - in Control of Vascular Function. Nat. Rev. Mol. Cel Biol 7, 359-371. doi:10.1038/nrm1911

Onishi, T., Nishizuka, T., Kurahashi, T., Arai, T., Iwatsuki, K., Yamamoto, M., et al. (2014). Topical bFGF Improves Secondary Lymphedema through Lymphangiogenesis in a Rat Tail Model. Plast. Reconstr. Surg. Glob. Open 2, e196. doi:10.1097/GOX.0000000000000154

Online Mendelian Inheritance in Man (2021). OMIM (TM). Johns Hopkins University, Baltimore, MD. MIM Number: $\{153100\}:\{06 / 04 / 2021\}$ : World Wide Web URL. Available at: http://www.ncbi.nlm.nih.gov/omim/ (Accessed November 15, 2021).

Palmieri, M., Di Sarno, L., Tommasi, A., Currò, A., Doddato, G., Baldassarri, M., et al. (2021). MET Somatic Activating Mutations Are Responsible for 
Lymphovenous Malformation and Can Be Identified Using Cell-free DNA Next Generation Sequencing Liquid Biopsy. J. Vasc. Surg. Venous Lymphat Disord. 9, 740-744. doi:10.1016/j.jvsv.2020.07.015

Pardi, N., Hogan, M. J., Porter, F. W., and Weissman, D. (2018). mRNA Vaccines a new era in Vaccinology. Nat. Rev. Drug Discov. 17, 261-279. doi:10.1038/nrd. 2017.243

Park, H. J., Yuk, C. M., Shin, K., and Lee, S. H. (2018). Interleukin-17A Negatively Regulates Lymphangiogenesis in T Helper 17 Cell-Mediated Inflammation. Mucosal Immunol. 11, 590-600. doi:10.1038/mi.2017.76

Perrault, D. P., Lee, G. K., Park, S. Y., Lee, S., Choi, D., Jung, E., et al. (2019). Small Peptide Modulation of Fibroblast Growth Factor Receptor 3-Dependent Postnatal Lymphangiogenesis. Lymphat Res. Biol. 17, 19-29. doi:10.1089/lrb. 2018.0035

Polack, F. P., Thomas, S. J., Kitchin, N., Absalon, J., Gurtman, A., Lockhart, S., et al. (2020). Safety and Efficacy of the BNT162b2 mRNA Covid-19 Vaccine. N. Engl. J. Med. 383, 2603-2615. doi:10.1056/NEJMoa2034577

Pytowski, B., Goldman, J., Persaud, K., Wu, Y., Witte, L., Hicklin, D. J., et al. (2005). Complete and Specific Inhibition of Adult Lymphatic Regeneration by a Novel VEGFR-3 Neutralizing Antibody. J. Natl. Cancer Inst. 97, 14-21. doi:10.1093/ jnci/dji003

Rautajoki, K. J., Kylaniemi, M. K., Raghav, S. K., Rao, K., and Lahesmaa, R. (2008). An Insight into Molecular Mechanisms of Human $\mathrm{T}$ Helper Cell Differentiation. Ann. Med. 40, 322-335. doi:10.1080/07853890802068582

Rockson, S. G. (2018). Lymphedema after Breast Cancer Treatment. N. Engl. J. Med. 379, 1937-1944. doi:10.1056/NEJMcp1803290

Rockson, S. G., and Rivera, K. K. (2008). Estimating the Population burden of Lymphedema. Ann. N. Y Acad. Sci. 1131, 147-154. doi:10.1196/annals.1413.014

Rockson, S. G., Tian, W., Jiang, X., Kuznetsova, T., Haddad, F., Zampell, J., et al. (2018). Pilot Studies Demonstrate the Potential Benefits of Antiinflammatory Therapy in Human Lymphedema. JCI insight 3, e123775. doi:10.1172/jci. insight. 123775

Rockson, S. G. (2001). Lymphedema. Am. J. Med. 110, 288-295. doi:10.1016/ s0002-9343(00)00727-0

Ruzicka, T., Bieber, T., Schöpf, E., Rubins, A., Dobozy, A., Bos, J. D., et al. (1997). A Short-Term Trial of Tacrolimus Ointment for Atopic Dermatitis. European Tacrolimus Multicenter Atopic Dermatitis Study Group. N. Engl. J. Med. 337, 816-821. doi:10.1056/NEJM199709183371203

Saaristo, A., Veikkola, T., Tammela, T., Enholm, B., Karkkainen, M. J., Pajusola, K., et al. (2002). Lymphangiogenic Gene Therapy with Minimal Blood Vascular Side Effects. J. Exp. Med. 196, 719-730. doi:10.1084/jem.20020587

Sahu, I., Haque, A. K. M. A., Weidensee, B., Weinmann, P., and Kormann, M. S. D. (2019). Recent Developments in mRNA-Based Protein Supplementation Therapy to Target Lung Diseases. Mol. Ther. 27, 803-823. doi:10.1016/j. ymthe.2019.02.019

Saito, Y., Nakagami, H., Morishita, R., Takami, Y., Kikuchi, Y., Hayashi, H., et al. (2006). Transfection of Human Hepatocyte Growth Factor Gene Ameliorates Secondary Lymphedema via Promotion of Lymphangiogenesis. Circulation 114, 1177-1184. doi:10.1161/CIRCULATIONAHA.105.602953

Salinas-Huertas, S., Luzardo-González, A., Vázquez-Gallego, S., Pernas, S., Falo, C., Pla, M. J., et al. (2021). Risk Factors for Lymphedema after Breast Surgery: a Prospective Cohort Study in the Era of sentinel Lymph Node Biopsy. Breast Dis. 41 (1), 97-108. doi:10.3233/bd-210043

Sano, M., Hirakawa, S., Suzuki, M., Sakabe, J. I., Ogawa, M., Yamamoto, S., et al. (2020). Potential Role of Transforming Growth Factor-Beta 1/Smad Signaling in Secondary Lymphedema after Cancer Surgery. Cancer Sci. 111, 2620-2634. doi:10.1111/cas.14457

Sapadin, A. N., and Fleischmajer, R. (2006). Tetracyclines: Nonantibiotic Properties and Their Clinical Implications. J. Am. Acad. Dermatol. 54, 258-265. doi:10.1016/j.jaad.2005.10.004

Savetsky, I. L., Ghanta, S., Gardenier, J. C., Torrisi, J. S., García Nores, G. D., Hespe, G. E., et al. (2015). Th2 Cytokines Inhibit Lymphangiogenesis. PLoS One 10, e0126908. doi:10.1371/journal.pone.0126908

Schindewolffs, L., Breves, G., Buettner, M., Hadamitzky, C., and Pabst, R. (2014). VEGF-C Improves Regeneration and Lymphatic Reconnection of Transplanted Autologous Lymph Node Fragments: An Animal Model for Secondary Lymphedema Treatment. Immun. Inflamm. Dis. 2, 152-161. doi:10.1002/ iid 3.32
Schmitz, K. H., Troxel, A. B., Dean, L. T., DeMichele, A., Brown, J. C., Sturgeon, K., et al. (2019). Effect of Home-Based Exercise and Weight Loss Programs on Breast Cancer-Related Lymphedema Outcomes Among Overweight Breast Cancer Survivors: The WISER Survivor Randomized Clinical Trial. JAMA Oncol. 5, 1605-1613. doi:10.1001/jamaoncol.2019. 2109

Secker, G. A., and Harvey, N. L. (2021). Regulation of VEGFR Signalling in Lymphatic Vascular Development and Disease: An Update. Int. J. Mol. Sci. 22, 7760. doi:10.3390/ijms 22147760

Shih, Y. C., Xu, Y., Cormier, J. N., Giordano, S., Ridner, S. H., Buchholz, T. A., et al. (2009). Incidence, Treatment Costs, and Complications of Lymphedema after Breast Cancer Among Women of Working Age: a 2-year Follow-Up Study. J. Clin. Oncol. 27, 2007-2014. doi:10.1200/JCO. 2008.18.3517

Shin, K., Kataru, R. P., Park, H. J., Kwon, B. I., Kim, T. W., Hong, Y. K., et al. (2015). TH2 Cells and Their Cytokines Regulate Formation and Function of Lymphatic Vessels. Nat. Commun. 6, 6196. doi:10.1038/ncomms7196

Skobe, M., Hawighorst, T., Jackson, D. G., Prevo, R., Janes, L., Velasco, P., et al. (2001). Induction of Tumor Lymphangiogenesis by VEGF-C Promotes Breast Cancer Metastasis. Nat. Med. 7, 192-198. doi:10.1038/84643

Skowronski, D. M., and De Serres, G. (2021). Safety and Efficacy of the BNT162b2 mRNA Covid-19 Vaccine. N. Engl. J. Med. 384, 1576-1577. doi:10.1056/ NEJMc2036242

Smith, K. A. (1988). Interleukin-2: Inception, Impact, and Implications. Science 240, 1169-1176. doi:10.1126/science.3131876

Sommer, T., Buettner, M., Bruns, F., Breves, G., Hadamitzky, C., and Pabst, R. (2012). Improved Regeneration of Autologous Transplanted Lymph Node Fragments by VEGF-C Treatment. Anat. Rec. (Hoboken) 295, 786-791. doi:10.1002/ar.22438

Sterne, J. A., Hernán, M. A., Reeves, B. C., Savović, J., Berkman, N. D., Viswanathan, M., et al. (2016). ROBINS-I: a Tool for Assessing Risk of Bias in Non-randomised Studies of Interventions. BMJ 355, i4919. doi:10.1136/bmj. i4919

Sterne, J. A. C., Savović, J., Page, M. J., Elbers, R. G., Blencowe, N. S., Boutron, I., et al. (2019). RoB 2: a Revised Tool for Assessing Risk of Bias in Randomised Trials. BMJ 366, 14898. doi:10.1136/bmj.14898

Stolldorf, D. P., Dietrich, M. S., and Ridner, S. H. (2016). Symptom Frequency, Intensity, and Distress in Patients with Lower Limb Lymphedema. Lymphat. Res. Biol. 14 (2), 78-87. doi:10.1089/lrb.2015.0027

Su, C., Yang, T., Wu, Z., Zhong, J., Huang, Y., Huang, T., et al. (2017). Differentiation of T-Helper Cells in Distinct Phases of Atopic Dermatitis Involves Th1/Th2 and Th17/Treg. Eur. J. Inflamm. 15, 46-52. doi:10.1177/ $1721727 \times 17703271$

Szőke, D., Kovács, G., Kemecsei, É., Bálint, L., Szoták-Ajtay, K., Aradi, P., et al. (2021). Nucleoside-modified VEGFC mRNA Induces Organ-specific Lymphatic Growth and Reverses Experimental Lymphedema. Nat. Commun. 12, 3460. doi:10.1038/s41467-02123546-6

Szuba, A., Skobe, M., Karkkainen, M. J., Shin, W. S., Beynet, D. P., Rockson, N. B., et al. (2002). Therapeutic Lymphangiogenesis with Human Recombinant VEGF-C. FASEB J. 16, 1985-1987. doi:10.1096/fj.02-0401fje

Tabibiazar, R., Cheung, L., Han, J., Swanson, J., Beilhack, A., An, A., et al. (2006). Inflammatory Manifestations of Experimental Lymphatic Insufficiency. Plos Med. 3, e254. doi:10.1371/journal.pmed.0030254

Tammela, T., and Alitalo, K. (2010). Lymphangiogenesis: Molecular Mechanisms and Future Promise. Cell 140, 460-476. doi:10.1016/j.cell. 2010.01 .045

Tammela, T., Saaristo, A., Holopainen, T., Lyytikkä, J., Kotronen, A., Pitkonen, M., et al. (2007). Therapeutic Differentiation and Maturation of Lymphatic Vessels after Lymph Node Dissection and Transplantation. Nat. Med. 13, 1458-1466. doi: $10.1038 / \mathrm{nm} 1689$

Tian, W., Rockson, S. G., Jiang, X., Kim, J., Begaye, A., Shuffle, E. M., et al. (2017). Leukotriene B4 Antagonism Ameliorates Experimental Lymphedema. Sci. Transl Med. 9, eaal3920. doi:10.1126/scitranslmed.aal3920

Trincot, C. E., and Caron, K. M. (2019). Lymphatic Function and Dysfunction in the Context of Sex Differences. ACS Pharmacol. Transl Sci. 2, 311-324. doi:10. 1021/acsptsci.9b00051 
ULTRA (2021). Ubenimex in Adult Patients with Lymphedema of the Lower Limb (ULTRA). Available at: https://ClinicalTrials.gov/show/NCT02700529 (Accessed November 15, 2021).

US prescribing information (2021). US Prescribing Information: Doxycycline. Available at: https://www.accessdata.fda.gov/drugsatfda_docs/label/2016/ 90431Orig1s010lbl.pdf (Accessed November 15, 2021).

US prescribing information (2021). US Prescribing Information: Ketoprofen. Available at: https://www.accessdata.fda.gov/drugsatfda_docs/label/2007/ 019816s011lbl.pdf (Accessed November 15, 2021).

US prescribing information (2021). US Prescribing Information: Protopic (Tacrolimus). Available at: https://www.accessdata.fda.gov/drugsatfda_docs/ label/2011/050777s018lbl.pdf (Accessed November 15, 2021).

U.S. Prescribing information (2021). GILENYA (Fingolimod). Available at: https:// www.accessdata.fda.gov/drugsatfda_docs/label/2018/022527s024lbl.pdf (Accessed November 8, 2021).

Uzkeser, H., Karatay, S., Erdemci, B., Koc, M., and Senel, K. (2015). Efficacy of Manual Lymphatic Drainage and Intermittent Pneumatic Compression Pump Use in the Treatment of Lymphedema after Mastectomy: a Randomized Controlled Trial. Breast Cancer 22, 300-307. doi:10.1007/ s12282-013-0481-3

Veikkola, T., Jussila, L., Makinen, T., Karpanen, T., Jeltsch, M., Petrova, T. V., et al. (2001). Signalling via Vascular Endothelial Growth Factor Receptor-3 Is Sufficient for Lymphangiogenesis in Transgenic Mice. EMBO J. 20, 1223-1231. doi:10.1093/emboj/20.6.1223

Walker, J., Tanna, S., Roake, J., and Lyons, O. (2021). A Systematic Review of Pharmacologic and Cell-Based Therapies for Treatment of Lymphedema (2010-2021). J. Vasc. Surg. Venous lymphatic Disord. 21, 486-488. doi:10. 1016/j.jvsv.2021.09.004

Wang, C., and Lin, A. (2014). Efficacy of Topical Calcineurin Inhibitors in Psoriasis. J. Cutan. Med. Surg. 18, 8-14. doi:10.2310/7750.2013.13059

Wang, X. (2021). Safety and Efficacy of the BNT162b2 mRNA Covid-19 Vaccine. N. Engl. J. Med. 384, 1577-1578. doi:10.1056/NEJMc2036242

Warren, A. G., Brorson, H., Borud, L. J., and Slavin, S. A. (2007). Lymphedema: a Comprehensive Review. Ann. Plast. Surg. 59, 464-472. doi:10.1097/01.sap. $0000257149.42922 .7 \mathrm{e}$

Wong, A. (2021). Role of Therapeutic Lymphangiogenesis in the Prevention and Treatment of Lymphedema. Boston Lymphatic Symp. (Unpublished). Available at: https://bostonlymphaticsymposium.org/ clinicalhome/agenda/

Yan, A., Avraham, T., Zampell, J. C., Haviv, Y. S., Weitman, E., and Mehrara, B. J. (2011). Adipose-derived Stem Cells Promote Lymphangiogenesis in Response to VEGF-C Stimulation or TGF-B1 Inhibition. Future Oncol. 7, 1457-1473. doi:10.2217/fon.11.121
Yoon, S. H., Kim, K. Y., Wang, Z., Park, J. H., Bae, S. M., Kim, S. Y., et al. (2020) EW-7197, a Transforming Growth Factor-Beta Type I Receptor Kinase Inhibitor, Ameliorates Acquired Lymphedema in a Mouse Tail Model. Lymphat Res. Biol. 18, 433-438. doi:10.1089/lrb.2018.0070

Yoon, Y. S., Murayama, T., Gravereaux, E., Tkebuchava, T., Silver, M., Curry, C., et al. (2003). VEGF-C Gene Therapy Augments Postnatal Lymphangiogenesis and Ameliorates Secondary Lymphedema. J. Clin. Invest. 111, 717-725. doi:10. 1172/JCI15830

Yuan, Y., Arcucci, V., Levy, S. M., and Achen, M. G. (2019). Modulation of Immunity by Lymphatic Dysfunction in Lymphedema. Front. Immunol. 10, 76. doi:10.3389/fimmu.2019.00076

Zampell, J. C., Elhadad, S., Avraham, T., Weitman, E., Aschen, S., Yan, A., et al. (2012). Toll-like Receptor Deficiency Worsens Inflammation and Lymphedema after Lymphatic Injury. Am. J. Physiol. Cel Physiol 302, C709-C719. doi:10. 1152/ajpcell.00284.2011

Zampell, J. C., Yan, A., Elhadad, S., Avraham, T., Weitman, E., and Mehrara, B. J. (2012). CD4(+) Cells Regulate Fibrosis and Lymphangiogenesis in Response to Lymphatic Fluid Stasis. PLoS One 7, e49940. doi:10.1371/ journal.pone.0049940

Zarkada, G., Heinolainen, K., Makinen, T., Kubota, Y., and Alitalo, K. (2015). VEGFR3 Does Not Sustain Retinal Angiogenesis without VEGFR2. Proc. Natl. Acad. Sci. U S A. 112, 761-766. doi:10.1073/pnas.1423278112

Zhu, J., Yamane, H., and Paul, W. E. (2010). Differentiation of Effector CD4 T Cell Populations $\left({ }^{*}\right)$. Annu. Rev. Immunol. 28, 445-489. doi:10.1146/annurevimmunol-030409-101212

Conflict of Interest: The authors declare that the research was conducted in the absence of any commercial or financial relationships that could be construed as a potential conflict of interest.

Publisher's Note: All claims expressed in this article are solely those of the authors and do not necessarily represent those of their affiliated organizations, or those of the publisher, the editors, and the reviewers. Any product that may be evaluated in this article, or claim that may be made by its manufacturer, is not guaranteed or endorsed by the publisher.

Copyright (C) 2022 Brown, Dayan, Coriddi, Campbell, Kuonqui, Shin, Park, Mehrara and Kataru. This is an open-access article distributed under the terms of the Creative Commons Attribution License (CC BY). The use, distribution or reproduction in other forums is permitted, provided the original author(s) and the copyright owner(s) are credited and that the original publication in this journal is cited, in accordance with accepted academic practice. No use, distribution or reproduction is permitted which does not comply with these terms. 